This report was prepared as an account of work sponsored by an agency of the United States Government. Neither the United States Government nor any agency thereof, nor any of their cmployees, makes any warranty, express or implied, or assumes any legal liability or responsibility for the accul acy, completeness, or issefulness of any information, apparatus, product, or process disclosed, or represents that its use would not infringe privately owned rights. Refer. ence herein to any specific commercial product, process, or service by trade name, Irademark, manufacturer. or otherwise does not necessarily constitute or imply its endorsement, recom. mendation, of favoring by the United States Government or any agency thereof. The views and opinions of authors expressed herein do not necessarily state or reflect those of the United States Government of any agency thereor.

\title{
SAVANNAH RIVER SITE COMPUTING STANDARDS AND GUIDELINES REFERENCE (U)
}

by

Computer Architecture and Standards Team

Westinghouse Savannah River Company

Savannah River Site

Aiken, South Carolina 29808

A technical report being deposited at OSTI

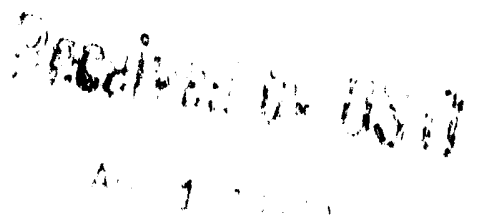

The information contained in this paper was developed during the course of work done under Contract No. DE-AC09-89SR 18035 with the U.S. Department of Energy. By acceptance of this
paper the publisher and/or recipient acknowledger nonexclusive, royalty-free license in and to any copyright U.S. Government's right to retain a to reproduce and to authorize others to reproduce to reproduce and to authorize others to reproduce all or part of the copyrighted paper. 
WSRC-IM-92-23

Controlled by Receipt

Copy

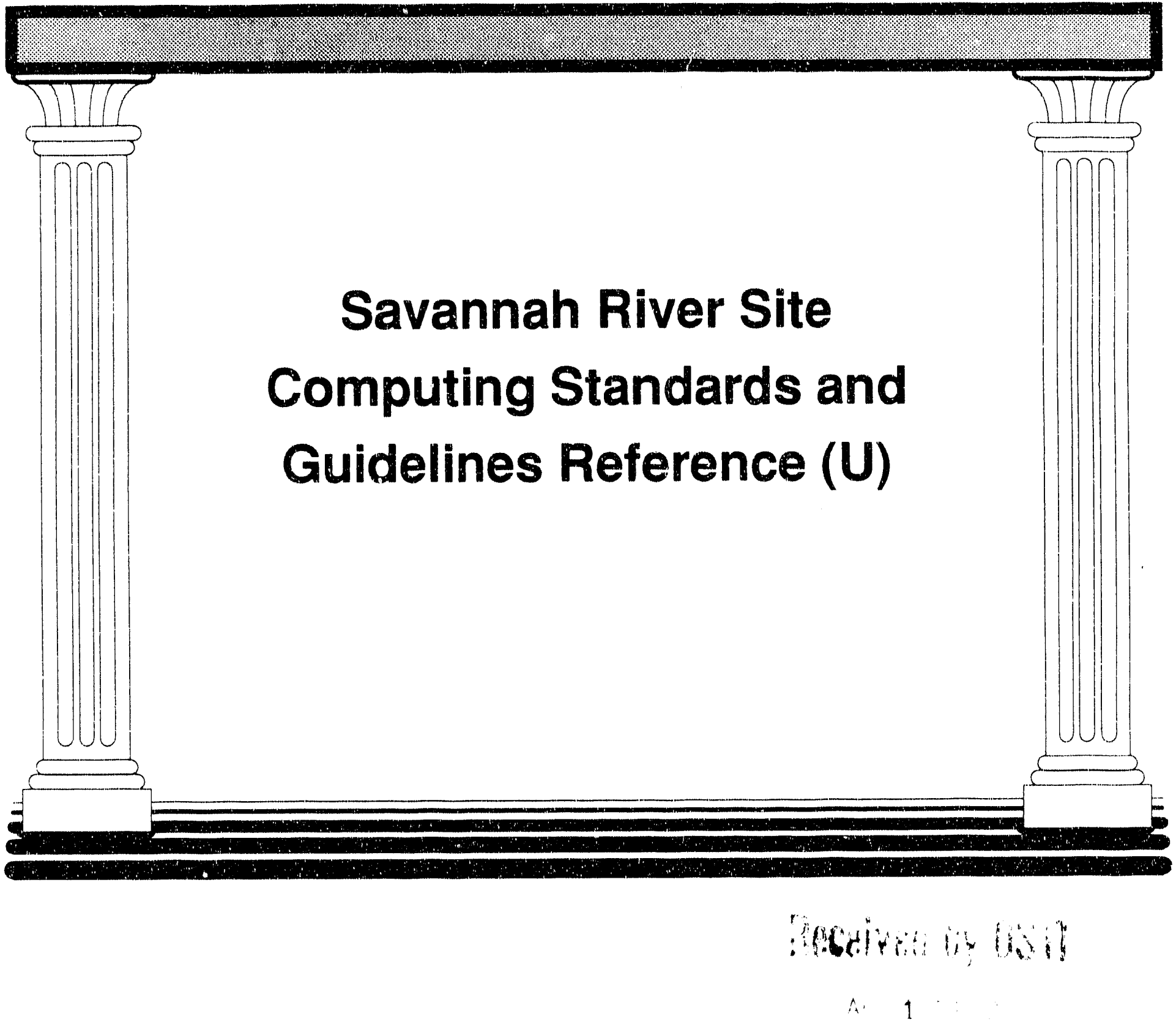

Computer

Architecture and

Westinghouse Savannah River Company

Standards

Savannah River Site

Team

Aiken, SC 29808

Prepared for the U. S. Department of Energy Under Contract No. DE-AC09-89SR18035 

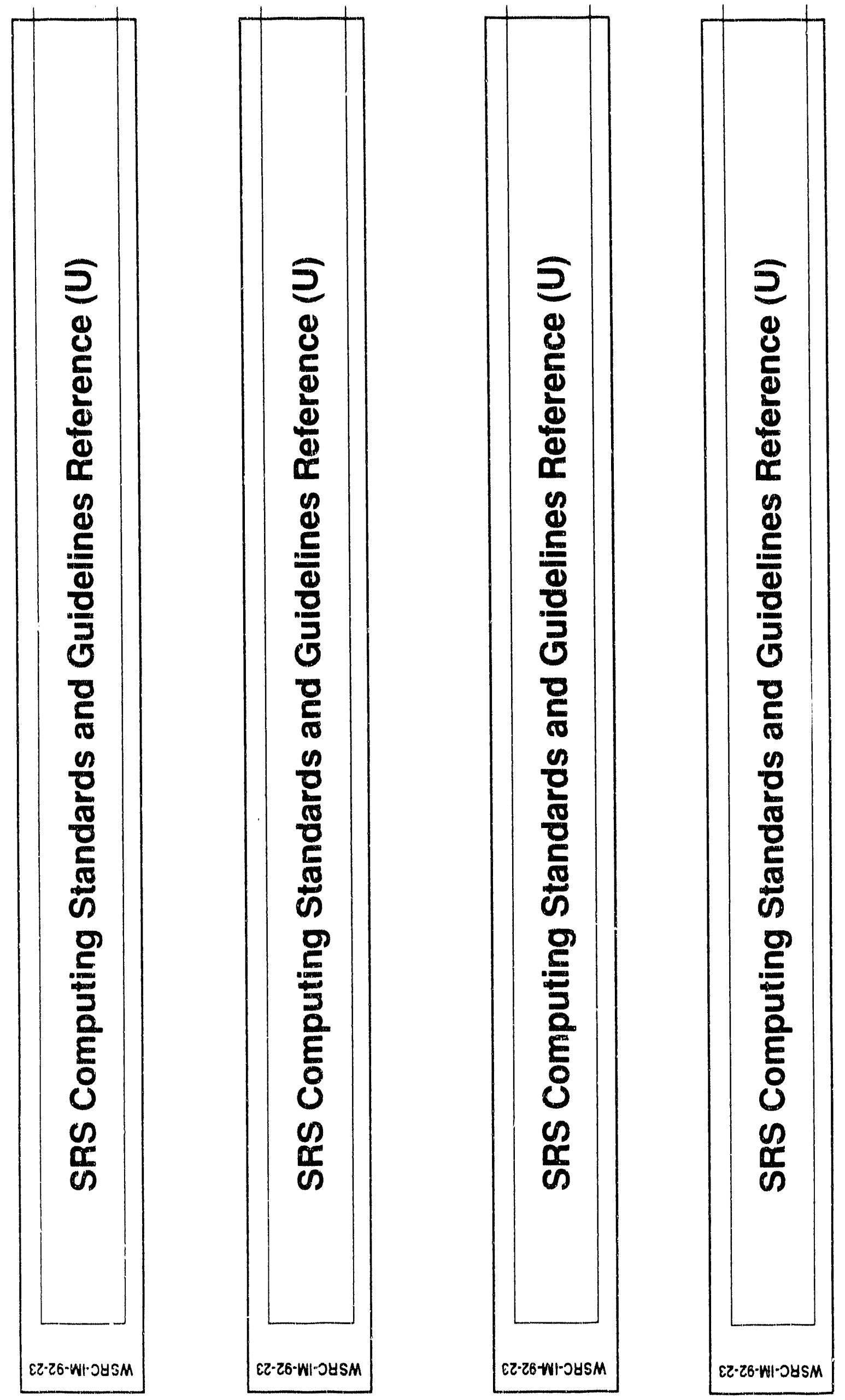


\section{Savannah River Site}

\section{Computing Standards and \\ Guidelines Reference (U)}

Publication Date: 4/1/92

Authorized Derivative Classifier

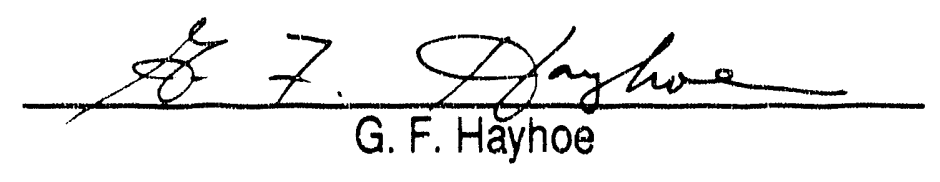

Computing

Architecture and

Standards

Team

Westinghouse Savannah River Company

Savannah River Site

Aiken, SC 29808

Prepared for the U. S. Department of Energy Under Contract No. DE-AC09-89SR18035 


\author{
Introduction (Rev 0, 4/1/92) \\ TO. 0 \\ Technology Guldellnes (R3v 0, 4/1/92) \\ T1.0 \\ T1.1 \\ Operating Systems Services Technology Group (Rev 0, 4/1/92) \\ T1.2 \\ POSIX (Rev 0, 4/1/92) \\ XPG3 (Rev 0, 4/1/92) \\ C2 Security (Rev 0, 4/1/92) \\ $\mathrm{T} 2.0$ \\ T2.1 \\ $\mathrm{T} 2.2$ \\ $\mathrm{T} 2.3$ \\ T3.0 \\ T3.1 \\ T3.2 \\ T3.3 \\ $\mathrm{T} 4.0$ \\ T4.1 \\ T4.2 \\ $\mathrm{T} 4.3$ \\ T4.4 \\ T4.5 \\ T4.6 \\ T5.0 \\ T5.1 \\ T5.2 \\ T5.3 \\ T5.4 \\ T5.5 \\ T5.6 \\ T5.7 \\ T5.8 \\ T5.9 \\ T5.10 \\ T5.11 \\ T 5.12 \\ User Interfaces Services Technology Group (Rev 0, 4/1/92) \\ $X$ Windows $(\operatorname{Rev} 0,4 / 1 / 92)$ \\ OSF/Motif (Rev 0, 4/1/92) \\ PEX (Rev 0, 4/1/92) \\ Program Services Technology Group (Rev 0, 4/1/92) \\ ANSI COBOL (Rev 0, 4/1/92) \\ ANSI FORTRAN (Rev 0, 4/1/92) \\ ANSI C (Rev 0, 4/1/92) \\ Data Management Services Technology Group (Rev 0, 4/1/92) \\ SQL (Rev 0, 4/1/92) \\ NFS/RPC (Rev $0,4 / \mathrm{i} / 92)$ \\ DCE (Rey $0,4 / 1 / 92$ ) \\ RDA $(\operatorname{Rev} 0,4 / 1 / 92)$ \\ DES (Rev $0,4 / 1 / 92)$ \\ DAL (Rev $0,4 / 1 / 92)$ \\ Data Interchange Services Technology Group (Rev 0, 4/1/92) \\ ODA/ODIF (Rev $0,4 / 1 / 92$ ) \\ SGML (Rev 0, 4/1/92) \\ CCITT III and IV (Rev 0, 4/1/92) \\ TIFF (Rev $0,4 / 1 / 92)$ \\ CGM (Rev 0, 4/1/92) \\ IGES (Rev 0, 4/1/92) \\ EDI (Rev 0, 4/1/92) \\ RTF (Rev 0, 4/1/92) \\ Postscript (Rev 0, 4/1/92) \\ X.400 (Rev $0,4 / 1 / 92)$ \\ X.500 (Rev $0,4 / 1 / 92)$ \\ ASCII (Rev 0, 4/1/92) \\ T6.0 \\ T6.1 \\ Graphics Services Technology Group (Kev 0, 4/1/92) \\ T6.2$$
\text { GKS (Rev 0, 4/1/92) }
$$ \\ PHIGS (Rev 0, 4/1/92)
}


T7.

T7.1

T7.2

$\mathrm{T} 7.3$

T7.4

T'7.5

T7.6

T7.7

T7.8

T7.9

T7.10

T7.11

T8.0

T8.1

T8. 2

T8.3

T8.4

T8.5

T8.6
Network Services Technology Group (Rev 0, 4/1/92)

Ethernet (Rev 0, 4/1/92)

Token Ring (Rev 0, 4/1/92)

FDDI (Rev 0, 4/1/92)

OSI (Rev 0, 4/1/92)

TCP/IP (Rev 0, 4/1,92)

DECnet / LAT (Rev 0, 4/1/92)

SNA (Rev 0, 4/1/92)

XNS / IPX (Rev 0, 4/1/92)

AppleTalk (Rev 0,4/1/92)

SNMP (Rev 0, 4/1/92)

Kerberos (Rev 0, 4/1/92)

Hardware Interfaces Technology Group (Rev 0, 4/1/92)

CD-ROM Disk Format (ISO 9660-1988) (Rev 0, 4/1/92)

RS-232 $(\operatorname{Rev} 0,4 / 1 / 92)$

RS-449/RS -422/RS-423 (Rev 0, 4/1/92)

V.35 $(\operatorname{Rev} 0,4 / 1 / 92)$

SCSI (Rev 0, 4/1/92)

Centronics (Rev 0, 4/1/92)

P0.0

Standard Products

Attachment A. Computing Acronyms and Terms

Attachment B, Organlzations Producing Standards Documents 


\section{Purpose}

It is WSRC policy that site computing activities be based on standards (Reference 1). The primary reasons for defining the site's computing standards and guidelines are to promote interoperability of site computing systems and to facilitate the portability of programs, applications, and data between computer systems. This policy is necessary to obtain increased flexibility and cost effectiveness in carrying out the site mission.

The SRS computing standards will depend heavily on national and international standards, although standardization on dominant proprietary standards and on specific products will be required to reduce the total number of computer products supported at the site to a more manageable set. In other words, the emphasis on standards will be two-fold: standardization on the technologies required for information and process control systems integration, and standardization on specific products in order to keep the number of specific computer products that must be supported on the site to a manageable and economical set. Ideally, standard products will conforn to the technology standards. However, there will be cases where existing standard products do not conform totally to the technology standards yet remain supported for reasons of continuity and economics.

A site-wide Computing Council has been formed (Reference 2) to coordinate and integrate computing activities at SRS. This organization consists of serior mancugement representing each site division. It oversees the development and implementation of the site strategic computing vision in support of the site mission. The working arm of the Computing Council is the Computing Architecture and Standards Team (CAST). CAST is made up of representatives from all site divisions as well as other organizations that represent communities interested in computing, such as the Process Digital Equipment Committee (PDEC), the Engineering/Scientific Computer Committee (ESCC), and the Management Informations Systems Committee. CAST membership is knowledgeable in computing technologies and the use of computing to help perform the site's mission. This body is instrumental in setting standards for site computing and creating the site's computing architecture, as well as recommending computing policies to the Computing Council for consideration.

\section{Technology Standards}

A computing lechnology standard is defined by some international, national, industry consortium, or individual corporation as a standard way of accomplishing specific computing tasks or functions. These standards are "open" in the sense that the governing bodies publish the specifications in cornplete detail so that vendors may develop products that conform to the standards. In many cases the governing body for a standard will test and certify those vendor products that conform to the technology standard. 
Computing Standards and Guldellnes Reference

Introduction
Document:

Section:

Page:

Issue Date:

Revision:
WSRC-1M-92-23

Introduction

2 of 4

$4 / 1 / 92$

Various international and national bodies are developing so called "open" system standards for computing to promote non-proprietary means of achieving this sort of interoperability and portability. Such organizations include:

International Standards Organization (ISO)

American National Standards Institute (ANSI)

Open Systems Foundation (OSF)

Institute of Electrical and Electronics Engineers (IEEE)

National Institute of Standards and Technology (NIST)

Insirument Society of America (ISA)

Attachment B to this reference provides a more comprehensive list of standards

organizations along with instructions on how to obtain standards documents.

The United States Government, in general, and the Department of Energy (DOE) in particular support these standards. As a standard matures, the government may mandate its use at government facilities. This has already occurred for computer communications protocols under the Government Open Systems Interconnection Profile (GOSIP) program (Reference 3).

This document defines the computing technologies adopted by CAST as site guidelines and represent those current and emerging technologies which are relevant to the site. These technologies provide a firm foundation for implementing the site computing architecture (Reference 4), in that they define specifications for interoperability and portability to which computing systems developed at or purchased by the site ideally should conform.

Technology standards can be characterized by their maturity and penetration in the computer industry as well as by their strategic importance for the future (Reference 5). Some standards are mature and well supported by the computer hardware and software manufacturers. Other standards are emerging; that is, they have been defined and generally accepted, but as yet few products implement the standard. In some cases the relevance of particular standards overlap. For example, a mature standard is likely to be superseded by an emerging one judged by the industry or the government to have more long term strategic importance. Implementers and purchasers of computer systems and applications often must choose between mature and emerging standards to support.

Today, many of the computer technology standards are in a state of flux. There are technologies for which multiple organizations are attempting to establish competing standards and others for which there is no existing or even emerging standard. The state of each of the technology standards defined in this document is explained to give some guidance to site personnel in choosing between standards. Because of the constant evolution of computer technology and standards, this document will be updated periodically. 
Reference 6 describes those technology standards endorsed for use by the U.S. Government. Reference 7 provides the Department of Energy policy in support of Automated Data Processing (ADP) standards.

\section{Standard Products}

\section{References}

In addition to providing guidelines on the use of technology standards, CAST is working to establish site standards for specific computing products. These standard products will be established by CAST via competitive procurements or via endorsement of existing site de facto standards.

Site personnel who purchase computing products should determine whether site standard products that can satisfy their requirements exist. If so, then the site standard products should be used. In many cases, the acquisition of the standard products will be facilitated. It is the intent of the site policy for computing standards, MP 3.11, to allow the use of non-standard products by exception only. Such exceptions will require justification. In addition, when a purchaser of computer equipment needs capabilities not supplied by site standard products, then it is incumbent on the purchaser to consider the site computing technology standards as defined here, as well as interoperability requirements with existing systems and standard products. Relevant technology standards should be included as requirements in the technical specifications that new purchased products or developed systems are to meet.

This document defines the computing products that have been established as standards by CAST. Standard products generally are compatible with the site computing architecture and technology guidelines, but may reflect tactical compromises dictated by cost, past practices, or the commercial availability of certain technologies.

1. WSRC 1-01, Management Policies, MP 3.11, "Computing Standards and Guidelines"

2. WSRC 1-01, Management Policies, MP 3.12, "Computing Coordination and Integration"

3. WSRC 1-01, Management Policies, MP 3.14, "Government Open Systems Interconnection Profile (GOSIP) Compliance"

4. WSRC-IM-91-18-1, Savannah River sw: Computing Architecture

5. Application Portability Profile (APP): The U.S. Government's Open System Environment Profile OSE/I Version 1.0. NIST Special Publication 500-187

6. Federal ADP and Telecommunications Standards Index, U. S. General Services Administration, Information Resources Management Service, April 1991 
Document: Section:

Page:

Issue Date:

Introduction
WSRC-IM-92-23

introduction

4 of 4

$4 / 4 / 92$

7. U.S. Department of Energy Order 1360.3B, Automatic Data Processing Standards, November 15, 1990

\section{Attachments}

Attachment A. Computing Acronyms and Terms

Attachment B. Organizations Producing Technology Standards 


\section{Technology Standards}

The National Institute of Standards and Technology (NIST) has categorized computing technologies required to support portability of applications into the following areas:

$\begin{array}{ll}\text { T1 } & \text { Operating Systems Services } \\ T 2 & \text { User Interfaces Services } \\ \text { T3 } & \text { Program Services } \\ \text { T4 } & \text { Data Management Services } \\ \text { T5 } & \text { Data Interchange Services } \\ \text { T6 } & \text { Graphics Services } \\ \text { T7 } & \text { Network Services }\end{array}$

This document uses these categories to group technology standards and adds an additional one:

\section{T8 Hardware Interfaces}

Many of the standards for computing technologies have been defined and published by international or national standards organizations. Attachment B to this document includes contact points for these organizations.

Table $\mathrm{T} 1$ is a summary of the technology standards guidelined in this document. Each technology is categorized as to its maturity and strategic importance. "Mature" standards are complete and have been well accepted by the computer industry, and implementing products are commercially available. A "strategic" standard is one judged to be important to the site architecture's goal of achieving interoperability of heterogeneous systems and applications across the site. Timing may be critical in choosing between competing mature (but not strategic) and strategic (but not yet mature) standards. These choices must necessarily be made on a case by case basis and depend on the current state of the standards.

Note that specific products are not regarded as "technologies." Thus, for example, Motif as a standard graphical user interface methodology that is implemented by various vendor products is included as a technology standard, but products that provide a similar service, such as Microsoft Windows and Macintosh Operating System, are not.

Many of the technology standards defined in this reference are standards recommended for use by the U. S. Government. These are indicated by reference to a relevant Federal Information Processing Standard (FIPS) publication. At this time, mandatory consideration of these technology standards is limited to those required under the GOSIP program (see Reference 3 listed in the Introduction to this Reference). 
Computing Standards and Guidelines Reference

Technology Standarda
Document:

Section:

Page:

Issue Date:

Revision:
WSRC-IM-92-23

TO.0

2 of 3

$4 / 1 / 92$

Table T1

Technology Standards Summary

Technology

Standard

Section

Mature* Strategic ${ }^{* *}$

Operating System Services

\begin{tabular}{|l|c|c|c|}
\hline POSD & T1.1 & $\checkmark$ & $\checkmark$ \\
\hline XPG3 & T1.2 & $\checkmark$ & $\checkmark$ \\
\hline C2 & T1.3 & $\checkmark$ & $\checkmark$ \\
\hline
\end{tabular}

User Interface Services

\begin{tabular}{|l|c|c|c|}
\hline X Windows & T2.1 & $\checkmark$ & $\checkmark$ \\
\hline OSF / Motif & T2.2 & $\checkmark$ & $\checkmark$ \\
\hline PEX & T2.3 & & $\checkmark$ \\
\hline
\end{tabular}

Program Services

\begin{tabular}{|l|c|c|c|}
\hline COBOL & T3.1 & $\sqrt{ }$ & $\checkmark$ \\
\hline FORTRAN & T3.2 & $\sqrt{ }$ & $\checkmark$ \\
\hline C & T3.3 & $\sqrt{ }$ & $\checkmark$ \\
\hline
\end{tabular}

Data Management Services

\begin{tabular}{|l|c|c|c|}
\hline SQL & T4.1 & $\checkmark$ & $\checkmark$ \\
\hline NFS/RPC & T4.2 & $\checkmark$ & \\
\hline DCE & T4.3 & & $\checkmark$ \\
\hline RDA & T4.4 & & $\checkmark$ \\
\hline DES & T4.5 & $\checkmark$ & $\checkmark$ \\
\hline DAL & T4.6 & $\checkmark$ & \\
\hline
\end{tabular}

Data Interchange Services

\begin{tabular}{|l|c|c|c|}
\hline ODANODIF & T5.1 & & $\checkmark$ \\
\hline SGML & T5.2 & $\checkmark$ & $\checkmark$ \\
\hline CCITT III and IV & T5.3 & $\checkmark$ & \\
\hline TIFF & T5.4 & $\checkmark$ & \\
\hline CGM & T5.5 & $\checkmark$ & \\
\hline IGES & T5.6 & $\checkmark$ & \\
\hline EDI & T5.7 & $\checkmark$ & $\checkmark$ \\
\hline RTF & T5.8 & $\checkmark$ & \\
\hline Postscript & T5.9 & $\checkmark$ & \\
\hline X.400 & T5.10 & $\checkmark$ & $\checkmark$ \\
\hline X.500 & T5.11 & & $\checkmark$ \\
\hline ASCII & T5.12 & $\checkmark$ & \\
\hline
\end{tabular}

Graphics Services

\begin{tabular}{|l|c|c|c|}
\hline GKS & T6.1 & $\checkmark$ & \\
\hline PHIGS & T6.2 & & $\sqrt{ }$ \\
\hline
\end{tabular}




\begin{tabular}{|c|c|c|c|c|}
\hline \multirow[b]{2}{*}{ Techwology } & \multicolumn{3}{|c|}{$\begin{array}{c}\text { Table T1 - Continued } \\
\text { Technology Standards Summary }\end{array}$} & \multirow[b]{2}{*}{ Strategic** } \\
\hline & Standard & Secllion & Mature* & \\
\hline \multirow{11}{*}{ Network Services } & Ethemet & $T+1$ & $\sqrt{ }$ & $\sqrt{ }$ \\
\hline & Token Ring & T1.2 & $\sqrt{ }$ & \\
\hline & FDDI & T7.3 & & $\sqrt{ }$ \\
\hline & OSI & $\mathrm{T} 7.4$ & & $\sqrt{1}$ \\
\hline & TCP/IP & $T 7.5$ & $\sqrt{ }$ & $\sqrt{ }$ \\
\hline & DECnet $/ \mathrm{ATT}$ & T7.6 & $\sqrt{ }$ & \\
\hline & SNA & T7.7 & $\sqrt{ }$ & \\
\hline & XNS/IPX & 57.8 & $\sqrt{ }$ & \\
\hline & AppleTalk & 77.9 & 4 & \\
\hline & SNMP & $\mathrm{T} 7.10$ & $\sqrt{ }$ & $\sqrt{ }$ \\
\hline & Kerberos & T7.11 & $\sqrt{ }$ & $\sqrt{ }$ \\
\hline \multirow{6}{*}{ Hardware Interfaces } & CD-ROM & $7 . \overline{8.1}$ & $\sqrt{ }$ & \\
\hline & RS.232 & 78.2 & $\sqrt{ }$ & \\
\hline & $\mathrm{RS}-449 / 422 / 423$ & $78 . j$ & $\sqrt{ }$ & \\
\hline & V.35 & 78.4 & $\sqrt{ }$ & \\
\hline & SCSI & 78.5 & i & \\
\hline & Centronics & 58.6 & $\sqrt{ }$ & \\
\hline
\end{tabular}

" Mature - Complete and well accepted by the computer infustry; implementing products are commercially available.

*" Strategic - Important towards completing site architecture. 


\section{Operating Systems Services Technology Group}

Dessription

Operating system services are the core services needed to operate and administer the application platform (the computer hardware) and provide an interface between applications software and the platform. Services in this area can be grouped as follows:

Kernel operations provide low level services necessary to create and manage processes, execute progrm ms, clock services, process signal services, and provide tiie services and inpul/output to and from system peripherals.

Commands and utilities include facilities for the operator (user) to interact with the system to do such things as executing commands (starting programs), listing files, printing files, etc.

System management includes capabilities to define and manage user access, devices, file systems, job accounting, queues, use authorization, and system backup.

Operating system security services are specified in terms of controlling the access of users and processes representing users to data, functions, hardware, and software resources of a system.

Standardization of operating system services greatly facilitates program portability. For example, most applications utilize the system file services. On most systems, the system interaction with the file system is unique $w$ that system and is a part of the application (often the major part) that must be reprogrammed to move the application to a different type of computer system.

Technology Standards

$\begin{array}{ll}\text { T1.1 } & \text { POSIX } \\ \text { T1.2 } & \text { XPG3 } \\ \text { T1.3 } & \text { C2 Security }\end{array}$

\section{Related Technology Standards}

T2.1 X Windows

T4.2 NFS/RPC

T4.3 DCE

T7.11 Kerberos 


\begin{tabular}{llr} 
Computing Standards and Guldellnes Reference & Document: & WSRC-IM-92.23 \\
& Sectlon: & Page: \\
& Issue Date: & of \\
Technology Standards & Revision: & $4 / 1 / 92$ \\
& & 0 \\
\hline
\end{tabular}

\title{
rosix
}

\author{
Associated Technology Grou'p \\ Operating Systems Services \\ Kemel Operations
}

\section{Description}

The Portable Operating System Interface standard - Part 1 (POSIX.1) defines a standard operating system interface and environment based on UNIX ${ }^{\mathrm{TM}}$ Operating System documentation to provide application portability at the source code level. The core requirements are a set of required services common to any programming language. These services include the creation and management of processes, execution of programs, interprocess communications facilities, file and directory management, and control of input/output processing to and from extemal devices. Applications that use POSIX programming interfaces to these operating system services are portable across POSIXcompliant operating systems.

This standard is alternatively known as FIPS Pub 142, ISO/IEC 9945-1, and IEEE 1003.1-1990. It is expected that POSIX will be implemented by most UNIX system vendors and some veridors of proprietary operating systems (DEC has announced plans to make VMS POSIX conformant, and IBM has a similar statement of direction for MVS).

Additional POSIX standards still under development include:

1003.2 - $\mathrm{C}$, Ada, and FORTRAN language bindings to 1003.1

1003.3 - Shell and utility facilities

1003.4 - Verification and testing methods

1003.5 - Real time facilities

1003.6 - Secure / Trusted system considerations

1003.7 - Network interface facilities

1003.8 - System administration

1003.9 - Graphical user interfaces

1003.10 - Open Systems standards profiles

1003.11 - Overall guide to POSIX and Open Systems standards profiles

\section{Advaritages}

- POSIX offers a standard programming interface to operating system services.

- Applications written using the $C$ language and only POSIX system calls should be portable across a great number of diverse platforms.

\section{Disadvantages}

- POSIX.1 is not a complete operating system environment description, and the other parts of POSIX dre still immature. 
Recommended Usage

POSIX is both mature and strategic for use at SRS. It should be used as a technical specification for operating system procurements and a reference for applications programmers wishing to develop portable applications.

Related Technology Standards

XPG3

Support Contact

IRM, Advanced Technology and Architecture Section

References

IEEE Std 1003.1-1990, IEEE Standard Portable Operating System Interface for Computing Environments

FIPS Pub 151-1, Posix: Portable Operating Systems Interface for Computing Environments 


\section{XPG3}

\section{Associated Technology Group}

Operating System Services

Kernel Operations

\section{Description}

The X/Open (consorium of UNIX users) Portability Guide Issue 3 (XPG3) is a UNIX ${ }^{\text {TM }}$ operating system definition that incorporates other less complete standards definitions. XPG3 is the most complete and open of the UNIX'M system standards. It contains the POSIX 1003.1 definition, parts of the OS! model, SQL, and X Windows. XPG3 defines its own standards for system utilities, portable shell scripts, storage media compatibility, and system facilities (i.e., stored memory and message queues). It also includes the ISAM file definition from Informix.

$\mathrm{X} /$ Open has created a conformance testing suite of over 5000 tests that an implementation of LNIX'M must pass to be considered XPG3 conformant. X/Open has licensed XPG3 conformance testing to a few UNIX ${ }^{\mathrm{TM}}$ system vendors such as DEC and HP. Unlike the OSF and UNIXTM International, X/Dpen is not promoting its own technologies through the XPG3 definition.

\section{Advantages}

- It offers a standard progranıming interface to operauing system services and utilities.

- $\quad$ XPG3 is the most complete and most open UNIX ${ }^{\mathrm{TM}}$ operating system definition.

Disadvantages

- $\quad$ XPG3 may still be incomplete in some areas.

\section{Recommended Usage}

XPG3 is both mature and of strategic importance. It should be used as a technical specification for operating system procurements and as a reference for applications programmers developing portable applications.

\section{Related Technology Standards}

POSIX.1

SQL.

$\mathrm{X}$ Windows

Support Contact

IRM, Advanced Technology and Architecture Section 
Computing Standards and Guldellnes Reference

Technology Standards
Document:

Section:

Page:

Issue Date:

Revision:
WSRC.IM-92.23

$\mathrm{T} 1.2$

2 of 2

$4 / 1 / 92$

References

X/Open Portability Guide Issue 3, Volumes 1-i, X/Open Company Lid., Prentice-Hall 


\section{C2 Security}

\section{Associated Technology Group}

Operating System Services

Security Services

Description

The Department of Defense (DoD) Trusted Computer System Evaluation Criteria (the Orange Book) was developed with three objectives in mind:

to provide guidance to manufacturers as to what to build into their new trusted commercial products to satisfy trust requirements for sensitive applications.

to provide users with a means to assess the degree of trust that can be placed in computer systems for the processing of classified or other sensitive information.

to provide users a basis for specifying security requirements in acquisition specifications.

The Orange Book criteria are divided into four divisions, $A, B, C$ and $D$, with $A$ representing the most comprehensive security. Division $C$ is divided into two classes, $C 1$ and $C 2$, where $C 2$ represents a higher class of security.

Computer systems containing $\mathrm{C} 2$ security features provide for discretionary (need-toknow) protection and for accountability of subjects and the actions they initiate. Discretionary access control allows users to specify and control sharing of data or information under their control. The access controls provide that system objects are protected from unauthorized access.

Under C2 security, users are uniquely identified and authenticated via a password process. C2 systems must also provide for audit records for any access of information contained in the system. System events such as user identification and authentication, file access, program initiation, and operator actions are logged in the audit records. These records contain audit event data, including date and time, user, type of event, and success or failure of the events.

\section{Advantages}

- $\quad$ Each user of the system is uniquely identified and can be assigned to one or more user groups.

- Access to system objects is based on individual or group rights.

- $\quad$ Audit trails track user activities.

- Custom audit trails are supported. 
Disadvantages

- Work is required to establish user and group identities.

- $\quad$ Audit trails consume system resources.

- It is difficult to evaluate overall security of a system from audit data without automated analysis tools.

\section{Recommended Usage}

$\mathrm{C} 2$ is a mature and strategic site standard. All classified multi-user systems (except process control) must conform to the C2 standard by July 15,1992 . C2 security is recommended for multi-user systems that presess Unclassified Controlled Nuclear Information (UCNI), that have a heterogeneous population base, or that might be vulnerable to attack by unauthorized personnel.

\section{Related Technology Standards}

None

\section{Support Contact}

Safeguards, Security, and Emergency Preparedness Department, Safeguards and Security Programs Section

\section{References}

DoD 5200.28-STD, Department of Defense Trusted Computer System Evaluation Criteria, December 1985

National Computer Security Center (NCSC) standards: NCSC.-TG-003-87 (access control), NCSC-TG-001-87 (audit), and CSC-STD-(002-85 (password management) 


\section{User Interfaces Services Technology Group}

\section{Description}

User interfaces services define how a user may interact with an application. Such interfaces define the applications programming interface (API) between application programs and the graphical displays seen and manipulated by users. That is, these services define the "look and feel" of an application as seen by its user, as well as the programming details in creating the interface. Increasingly, the trend towards client-server computing allows the user interface to be on the personal workstation and the application on some remote "host" computer. Standards for User Interface Services permit the transmission of user interface "commands" across a network between the user workstation and the host application.

Industry trends are such that computer system manufacturers still define proprietary user interface services. The look and feel of these graphical user interfaces (GUT) are converging, but the programming interfaces remain unique for each system. Thus, the use of Microsoft Windows, lBM OS/2, or Apple Macintosh applications (the three most prominent examples of graphical user interfaces on personal computers) can appear very similar to users, but the programming required to create these applications is quite different among the three platforms.

The technology standards listed below are non-proprietary industry standards that are implemented on many different computer systems. As yet they do not replace the proprietary GUIs such as those listed above, but they are important in applications involving graphical user interfaces across a network of heterogeneous computer systems.

Technology Standards

$\begin{array}{ll}\text { T2.1 } & \text { X Windows } \\ \text { T2.2 } & \text { Motif } \\ \text { T2.3 } & \text { PEX }\end{array}$

\section{Related Technology Standards}

\section{T1.1 POSIX \\ T1.2 XPG3}




\section{$X$ Windows}

\section{Associated Technology Group}

User Interface Services

\section{Description}

The X Window System, or X, is a network-transparent window system that was developed at MIT in 1984. Since then, several versions have been developed, the most recent of which is X Version 11.5 (X11). X11 has been adopted as an industry-standard windowing system. $X$ is supported by a consortium of industry leaders such as DEC, Hewlett-Packard, Sun, IBM, and AT\&T that have united to direct, contribute to, and fund the continuing development of $\mathrm{X}$. Almost all workstation vendors have accepied the $\mathrm{X}$ Window System as a standard interface to their workstation hardware. In addition to the system software development directed by the consortium, many independent developers are producing application software for use with $X$.

\section{Advantages}

- $\quad \mathrm{X}$ provides a platform-independent graphical user interface (GUT ) mechanism supported by all strategic SRS computer vendors.

- $\quad \mathrm{X}$ supports the client-server applications architecture with the interface controlled by the application, not the workstation.

\section{Disadvantages}

- $X$ does not define the look and feel of graphical applications; it only provides a mechanism for them. It is a necessary component of a window system standard but not sufficient to ensure similar look and feel.

- $\mathrm{X}$ typically consumes more resources and is slower than native, proprietary GUIS such as Macintosh.

\section{Recommended Usage}

The $\mathrm{X}$ Window System is mature and a strategic technology for use at SRS. It is appropriate for applications using a GUI that must be delivered to workstations from multiple vendors' products using different native GUI interfaces.

\section{Related Technology Standards}

OSF/Motif

PEX

\section{Support Contact}

IRM, Advanced Technology and Architecture Section 
Computing Standards and Guldelines Reference

Technology Standards
Document:

Section:

Page:

Issue Date:

Revision:
WSRC-IM-92-23

T2.1

2 of 2

$4 / 1 / 92$

References

Sheiffler, Gettys, Newman, $X$ Window System, Digital Press

FIPS Pub 158, The User Interface Component of the Application Portability Profile 


\section{OSF/Motif}

\section{Associated Technology Group}

User Interface Services

\section{Description}

OSF/Motif, defined by the Open Systems Foundation (OSF), is a set of Application Programming Interfaces (API) combined with an $X$ Window manager which define the look and feel of applications using the X Window System. These APIs take the form of widgets and intrinsics to use the $\mathrm{X}$ Window System terminology. A widget or intrinsic is typically a graphical construct like a scroll bar or a standard way of decorating windows. Since OSF/Motif defines these constructs and the window manager, application developers are, iven the means to build applications which look consistent and behave consistently.

It should be noted that while there are competing definitions for X Window System look and feel, all such definitions are fully interoperable.

The OSF promotes the use of Motif as a graphical wi:er interface (GUT) standard by licensing source code of a reference implementation.

\section{Advantages}

- OSF/Motif is supported by most major workstation vendors (IBM, DEC, Apple, HP).

Disadvantages

- OSF/Motif is not supported by Sun, which currently has the greatest market share in the Unix workstation market.

Recommended Usage

OSF/Motif is both mature and strategic, and is useful both as a specification for the native GUI of a workstation and as an API for application development.

\section{Related Technology Standards}

$X$ Windows

PEX

\section{Support Contact}

IRM, Advanced Technology and Architecture Section 
Document:

Sectlon:

Page:

Issue Date:

Revision:
WSRC-IM-92-23

$\mathrm{T} 2.2$

2 of 2

4/1/92

\section{References}

The OSF/Style Guide and The OSF/Motif Users Guide, Open Systems Foundation, Inc. 


\section{PEX}

\section{Associated Technology Group}

User Interface Services

\section{Description}

PEX stands for Protocol Extensions to X. PEX represents the addition of ? support into the $\mathrm{X}$ protocol. PEX is most often associated with the Progrinitr..., Hierarchical Integrated Graphics Standard (PHIGS) and once stood for PHKS ...., usions to X. PEX as currently defined is more general than simply PHiIGS support. It could provide support for another 3-D graphics representation. However, it currently is implemented only for PHIGS. PEX represents a set of extensions to the $\mathrm{X}$ protocols that provide the ability to distribute 3-D graphics objects in a heterogeneous environment.

PEX is the result of the efforts of the PEX Interoperability Group, a group of 10 companies working with the blessings of the $\mathrm{X}$ Windows Consortium.

One of the major differences between PEX and $X$ is that while $X$ is limited to a set of 2-D integer screen coordinates, PEX supports the creation and transmission of 3-D floatingpoint coordinates. PEX extends the X Window System to support the rendering of 3-D shapes in the same way that 2-D graphics are controlled in $X$ Windows. PEX enables X applications to take advantage of 3-D hardware capabilities available in many highperformance workstations. It must be understood that PEX is not an API but an extension to the $\mathrm{X}$ protocol.

The current version of PEX will be available on the latest release tape X11R5 from the MIT X Consortium (Cambridge, MA).

\section{Advantages}

- PEX conserves network bandwidth by transmitting only changes to 3-D shapes over the network.

\section{Disadvantages}

- Because $X$ and PHIGS operate in some fundamentally different ways, PEX is unable to deal with some PHIGS error conditions.

\section{Recommended Usage}

PEX is strategic for use at SRS but not yet mature. It should be used as a technical specification for graphics system procurements and as a reference for application developers building networked graphics applications.

\section{Related Technology Standards}

$X$ Windows

PHIGS 
Support Contact

IRM, Advanced Txhmology and Architecture Section

Reterences

PEX, MIT X Consortium, X.11Rs 


\title{
Program Services Technology Group
}

\section{Description}

The procedural aspect of a computer application is embodied in the programming languages used to code it. There are hundreds of different programming languages, and it is not atypical that different system manufacturers' implementations of the same programming languages are different enough to make portability of computer applicaticns between heterogeneous computer systems a difficult task.

Tise lachnology standards in this group represent industry standards for some of the more common programming languages. Adherence to these standards will greatly facilitate the portability of computer applications. Programmers must be aware, however, that many computer manufaturers support these language standards as a base set but in many cases extend the language with additional functionality, which is not generally portable between systems. Thus, if application portability of an application is a goal, the programmer must take care to use only those language fcatures or consinuts defined by the standard for that language.

In many cases, application portability is not a goal when an application is written. However, computer applications often outlive the computer hardware on which they run, necessitating a port to another system. This fact is another reason for choosing a standard programming language with which to build the application. There are, however, legitimate reasons for using nonstandard languages or features to build cornputer applications. Ultimately, the developer must weigh the benefits derived from using a nonstandard language versus the difficulty of transferring the code to a different computer system at some future time.

Several languages used at SRS are not listed below. In some cases, these languages are proprietary to a particular vendor. In other cases, the languages are relatively new and the standards efforts have not yet been completed. The list of standards for programming languages listed here is not intended to imply that these should be used exclusively for programming systems at SRS. However, if one of the languages listed below is used, the standard implementation of that language as described here should be employed.

\section{Technology Standards}

\author{
T3.1 ANSI COBOL \\ T3.2 ANSI FORTRAN \\ T3.3 ANSI C
}


Computing Standards and Guldellnes Reference

Technology Standards
Document: WSRC-IM-92.23

Sectlon:

Page:

Issue Date:

Revision:
T 3.0

2 of 2

$4 / 1 / 92$

Related Technology Standards

T1.1 POSIX

T4.1 SQL

T6.1 GKS

T6.2 PHIGS 


\section{ANSI COBOL}

\section{Description}

COBOL is designed for programming self-documenting business oriented applications and has been in use since the early 1960 s. It is very common for business applications developed on central computer systems, but it is also commonly available for most midsize (minicomputers) and small computer systems (microcomputers). It is the most widespread programming language in use today and is a very mature standard.

The U.S. Government Federal Information Processing Standard (FIPS) and international standards (ISO) for COBOL are based on the American National Standards Institute (ANSI) standard, ANSI X3.23-1985 and Addendum X3.23A-189.

\section{Advantages}

- It is well supported by most vendors.

- It is suitable for general purpose business and financial applications.

- Many Computer Aided Systems Engineering (CASE) tools generate COBOL code.

\section{Cisadvantages}

- $\quad$ COBOL has very limited utility for computationally intensive applications as well as other types of applications such as real--time and communications.

- Newer fourth generation languages provide more powerful database manipulation capabilities.

\section{Recommended Usage}

COBOL is inth a mature and a strategic technology standard. It is recommended for the development of general business applications where program portability is a concern.

\section{Related S'randards}

None

Support Contact

IRM, Information Systems Engineering Section

\section{References}

FIPS Pub 21-3, COBOL

ANSI X3.23-1985, COBOL

ANSI X3.23A-1989, Adendum I, Intrinsic Function Module 


\section{ANSI FORTRAN}

\section{Associated Technology Group}

Programming Services

\section{Description}

FORTRAN (FORmula TRANslator) is a general purpose programming language with capabilities for performing virtually any type of application function. It was originally developed to assist in the development of scientific and engineering calculations and models, but it has been used for business and process control applications as well. It remains the language most often used for scientific applications.

The language has evolved with added capabilities suc. us structured programming constructs. The latest FIPS is based on the ANSI standard (ANSI X.3.9.1978), called FORTRAN-77. ANSI and ISO have recently adopted a new standard, FOR'RAN-90. FORTRAN-90 is a superset of FORTRAN-77 and includes new capabilities including dynamic allocation of array, whole array operations, pointer data types, and data structures.

FORTRAN-77-compliant compilers are readily available for supercomputers, mainframes, minicomputers, and microcomputers.

FORTRAN-90 implementations are not yet generally available.

\section{Advantages}

- Mature, well supported by all major system vendors (FORTRAN-77).

- Suitable for scientific calculation applications.

\section{Disadvantages}

- Proprietary extensions to the language are often introduced by systems vendors, reducing the portability of FORTRAN applications.

\section{Recommended Usage}

FORTRAN is both a mature and a strategic technology standard. FORTRAN-77 is recommended for the development of scientific/engineering applications, especially where program portability is a concern. Specify FORTRAN-90 as desirable for future use.

Related Standards 
Computing Standards and Guldellnes Reference

Technology Standards
Document:

Section:

Page:

Issue Date:

Revision:
WSRC.IM-92-23

T3.2

2 of 2

$4 / 1 / 92$

Support Contact

SRTC, Scientific Computations Section

References

FIPS Pub 069-1, FORTRAN

ANSI X3.9-1978, FORTRAN (FORTRAN-77)

ANSI X3.198-1991, FORTRAN (FORTRAN.90) 


\section{ANSI C}

\section{Associated Technology Group}

Programming Services

\section{Description}

$\mathrm{C}$ is a general purpose programming language with capabilities for performing virtually any type of application function. It was originally developed to assist in the development of the UNIX operating system and UNIX utilities, and thus has powerful operators for use in the development of system level software. It can also be used in the development of business, process control, and scientific applications. $\mathrm{C}$ has become the industry standard language for the development of applications for personal computers. It includes facilities for every level of programming, from low level (hardware control) operations to high level abstract functions and procedures. Data structuring, reusable library support, and memory management are included.

The language has evolved over the last 15 years. The latest FIPS and ISO (draft) standards are based on the ANSI standard (1989) under the control of the ANSI X3J11 committee. The ANSI X3 committee is considering the development of a second language standard for object oriented programming (OOP) based upon $\mathrm{C}$. This language is called $\mathrm{C}++$.

ANSI C-compliant compilers are readily available for supercomputers, mainframes, minicomputers, and microcomputers.

\section{Advantages}

- $\quad$ C is mature and well supported by all major system vendors.

- It is suitable for a wide variety of applications, especially on personal computers, operating systems, and real-time applications.

\section{Disadvantages}

- Complex syntax and powerful operations require relatively long times for programmers to master.

\section{Recommended Usage}

$\mathrm{C}$ is both a mature and a strategic technology standard and is recommended for the development of system level and process control applications where program portability is a concern.

\section{Related Standards}

None 
Computing Standards and Guldellnes Reference

Document:

Section:

WSRC-IM-92-23

Page:

T3.3

Issue Date:

Technology Standards

Revision:

Support Contact

IRM, Information Systems Engineering Section

References

FIPS Pub $160, C$

ANSI X3.159-1989, Programming Language C 


\section{Data Management Services Technology Group}

\section{Description}

Central to most systems is the management of data that can be defined independent of the processes that create or use it, maintained indefinitely, and shared among processes. Data management services include the following:

Data dictionary / directory services allow users and programmers to access and modify data about data, called metadata.

Database management system (DBMS) services provide controlled access and modification of structured data. DBMS systems provide for concurrent access of data by multiple users or processes, supporting features to create, populate, move, retrieve, archive, backup, and restore data.

Distributed data services provide access to and modification of data in remote (across a network) databases.

Data management security services include control of access to and integrity of data stored in a system through specific mechanisms in the data management software.

Most data management services are proprietary to the computer software vendors. Since most computer applications depend on extensive data management services, this fact greatly restricts the portability of computer applications utilizing those services. Also, applications often require data from a variety of sources. That is, they need distributed data services. These two facts are driving current efforts to establish standards in the data management services area.

\section{Technology Standards}

T4.1 SQL

T4.2 NFS/RPC

T4.3 DCE

T4.4 RDA

T4.5 DES

T4.6 DAL

\section{Related Technology Standards}

\section{T1.) POSIX \\ T7.11 Kerberos}


Computing Standards and Guldellnes Reference

Technology Standards
Document:
WSRC-IM-92-23

$\mathrm{T} 4.1$

1 of 2

$4 / 1 / 92$

\section{SQL}

Associated Technology Group

Data Management Services

Description

Structured Query Language (SQL) defines the basic elements and operations of a relational database management system. The ANSI standard (X3.135-1989 and ISO 9075:1989) provides functions for designing, accessing, maintaining, controlling, and protecting a database. The standard does not define a secure DBMS, but it does provide mechanisms for defining secure interfaces to the DBMS. SQL includes integrity constraints, and language bindings to COBOL, Pascal, FORTRAN, and PL/1. The associated embedded SQL standard (ANSI X3.168-1989) adds Ada and C to the list of high level language interfaces.

SQL is a mature standard that has been adopted as the DBMS component of X/OPEN, OSF, SQL-Access, and other vendor consortia. The level of conformance to the standard varies between vendors (level 1, level 2, and integrity constraint), but all major vendors are committed to providing upwardly compatible products to the standard's planned revisions and extensions. The SQL FIPS requires level 2 SQL compliance and the flagging of any vendor supplied extensions. The next version of the ANSI standard (1992 +) will include additional features for schema manipulation, dynamic SQL, exception handling, enhanced integrity constraints, transaction management, and data administration. A future version (1995+) will include distributed database management functions and support for object-oriented database management.

Advantages

- Applications developed in compliant SQL are transportable across platforms.

\section{Disadvantages}

- Many vendors built proprietary extensions to ANSI standard SQL, limiting portability of application software.

- Until user-friendly SQL front ends are widely available, computer professionals are required to build SQL-compliant DBMS applications.

- The existing standard is specified for stand-alone, single environment databases (see 1995 future enhancements).

\section{Recommended Usage}

ANSI SQL is mature and is a strategic site tecinology standard. It is recommended as the standard access language for relational database management systems (RDBMS). RDBMS built upon SQL features are more portable and will have a larger pool of programers available to maintain them throughout their life cycle. 
Computing Standards and Guldelines Reference

Technology Standards
Document: WSRC-IM-92.23

Section:

Page:

Issue Date:

Revision:
T4.1

2 of 2

$4 / 1 / 92$

Support Contact

IRM, Information Systems Engineering Section

References

ANSI X3.135-1989, Database Language SQL with Integrity Enhancements

ANSI X3.168-1989, Database Language Embedded SQL

FIPS Pub 127-1, Database Language SQL 


\title{
NFS/RPC
}

\section{Associated Technology Group}

\section{Data Management Services}

\section{Description}

The Network File System (NFS) is a mechanism for sharing files across a network which preserves the semantics of local file access. NFS was created by Sun Microsystems Inc. and has become a de facto industry standard. Implementations exist for every major computer platform. NFS is based on TCP/IP and is generally associated with UNIX environments where it is ubiquitous.

NFS is implemented with Open Network Computing (ONC) Remote Procedure Call (RPC) technology. Remote procedure calls extend the notion of a local procedure call to embrace interactions between components of distributed systems. XDR (External Data Representation) provides for the exchange of binary data between heterogeneous systems with remote procedures and handles translations between different internal data formats.

\section{Advantages}

- NFS/RPC is supported by all major computer vendors. It is the de facto industry standard.

\section{Disadvantages}

- NFS has some security holes and lacks robustness and scalability.

- It is likely to be replaced as the industry standard by DCE.

\section{Recommended Usage}

NFS/RPC is a mature but not strategic technology standard. It represents the most mature implementations for remote file system and remote procedure calls but is expected to be supplanted by OSF's DCE in the future as the industry standard endorsed by the international and national standards groups. Use NFS for near term requirements, but specify DCE as a desirable feature in any procurement specifications.

\section{Related Technology Standards}

TCP/IP

DCE

\section{Support Contact}

\author{
IRM, Advanced Technology and Architecture Section
}


Computing Standards and Guldellnes Reference

Technology Standards
Document: Section:

Page:

Issue Date:

Revision:
WSRC-IM-92-23

$\mathrm{T} 4.2$

2 of 2

$4 / 1 / 92$

References

RFC 1094, Network File System Protocol

RFC 1057, Remote Procedure Call 


\title{
DCE
}

\section{Associated Technology Group}

Data Management Services

Distributed Data Services and Data Management Stcurity Services

\author{
Description
}

The Open Software Foundation (OSF) is a consortium of computer systems and software vendors which uses an open process to define standard technologies. These technologies are then made available in the form of source code implementations on certain reference platforms to members who port the code to their specific platforms and offer it as a binary product to end users. To generate these "standards," the OSF issues a Request For Technology (RFT). Anyone may respond with technology that meets all or part of the specification. Responses are evaluated and merged 10 form the reference implementation. The Open Software Foundation Distributed Computing Environment (OSF/DCE) covers a wide range of communications services supporting a client-server infrastructure. The services include a Distributed File System (DFS), remote procedure call (RPC), directory service, time service, security service, and threads.

The DFS is based on the Andrew File System (AFS) from Carnegie-Mellon University. It is a client-server file system that combines local and remote storage into a single, expanded file systen with the location of individual files largely transparent to individual users. Directories, volumes, and entire servers may be replicated, providing reliability in the event of server failure. File caching is used to provide near local performance for remote file access.

The RPC portion of DCE includes high-level interface definition languages together with remote procedure calls. The interface definition languages are supported by compilers that convert high-level interface descriptions of remote procedures into $C$ language source code. The resulting remote procedure calls extend the notion of a local procedure call to embrace interactions between components of distributed systems. DCE RPC is an enhanced version of Hewlett-Packard's Network Computing System (NCS).

The naming service maps information about network resources to widely accessible, meaningful names. It allows users and programs to refer to servers, files, disks, people, etc. by convenient names without knowing where they are located in a network. DCE naming service represents a combination of the DEC Distributed Naming Service (DECdns) and DIR-X X.500 service from Siemens.

The time service provides a clock synchronization service for component systems of a distributed environment. This feature is required by many distributed systems in order to determine the order of events or the intervals between events. The time service was contributed by DEC as the Distributed Time Synchronization Service (DECdts). 
The DCE security service provides facilities for supporting confidentiality in remote procedure calls, a means for authenticating users and services, management of access permissions, and a registry for user account information. This technology is based on the Kerberos authentication system of MTT's Project Athena.

Threads are a technique for allowing multiple sequential flows of control within a single process. The DCE services all use threads, and OSF felt it was necessary to bundle a facility for providing threads into DCE so that implementations would not be constrained by operating systems that do not provide them.

\section{Advantages \\ - Offers an integrated collection of services for a distributed computing environment. \\ - Committed to by many major computer vendors.}

\section{Disadvantages}

- This is an emerging standard and is not widely implemented.

- In some areas, OSF/DCE competes with the Open Network Computing (ONC) environment from UNIX ${ }^{T M}$ International. ONC represents more of a collection of existing distinct services.

\section{Recommended Usage}

DCE is a strategic technology standard that is not yet mature. It should be used as a technical specification for network-Lased applications, especially those involving a heterogeneous computing environment.

\section{Related Technology Standards}

TCPIP

NFS

Kerberos

X.500

Suppon Contact

IRM, Adyanced Tectinology and Architecture Section

References

Distributed Computing Environmem, An Overview, Open Systems Foundation, Inc., April 1991 


\section{RDA}

\section{Associated Technology Group}

Data Management Services

Distributed Data Services

\section{Description}

Remote Database Access (RDA) is an ISO draft standard that defines the interface required to establish a remote connection between some client application program and a database server. This interface defines the process that controls data transfers to and from the database, with emphasis on the SQL data access language. RDA allows client applications to establish connections to a variety of relational database management systems (RDBMS). Under RDA, SQL statements are sent across a network to the RDA server as a set of character strings, and the resulting data or exception conditions are returned.

This standard is currently undergoing draft approval balloting in the joint ISO/IEC (International Electrotechnical Committee) Joint Technical Committee 1 (JTC1). Several RDBMS vendors have developed early implementations for testing and have demonstrated the ability to access data in a heterogeneous RDBMS environment at industry trade shows.

The existing specification does not consider multiple simultaneous connections between a client and rnultiple servers. RDA assumed a standards-based network. Early implementations use OSI-compliant networks. TCP/IP-based networks will also be employed in RDA applications.

Final adoption of the RDA standard and the release of commercially available products are expected during 1992. At that time, RDA is expected to become a key information systems integration strategy at SRS.

\section{Advantages}

- $\quad$ RDA is promised support by most major RDBMS vendors.

- $\quad$ An ISO international standard will force wide vendor support, likely to be included in future GOSIP requirements.

- It rests upon SQL, TCP/P, and OSI standards.

\section{Disadvantages}

- RDA is not yet commercially available.

- RDA supports single connections only.

\section{Recommended Usage}

Since RDA is an immature but strategic technology, it should be used as a nonmandatory technical specification for relational database management system and application and engineering developinent tool procurements. 
Computing Standards and Guldellnes Reference

Technology Standards
Document: Section:

Page:

Issue Date:

Revision:
WSRC.IM-92.23

$\mathrm{T} 4.4$

2 of 2

$4 / 1 / 92$

Related Technology Standards

SQL

TCP/IP

GOSIP

Support Contact

IRM, Advanced Technology and Architecture Section

References

ISO/IEC DP 9759, Remote Data Access (RDA) 


\section{DES}

\section{Associated Technology Group}

Data Management Services

Data Management Security Services

\section{Description}

The Data Encryption Standard (DES) is formally defined in ANSI X3.92-1981/R1987 and Federal Information Processing Standard Publication Number 46 (FIPS Pub 46). DES is one of the most widely used encryption systems today. It was developed in the 1970s and patented by researchers at IBM. IBM later made DES available for public use, and it was adopted as a standard.

DES is a bit permutation, substitution, and recombination function performed on blocks of 64 bits of data and 56 bits of key (eight 7-bit characters). The 64 bits of input are permuted initially, and then are input to a function using static tables of permutations and substitutions. The bits are permuted in combination with the 48 bits of the key in each round. This process is iterated 16 times (rounds), each time with a different set of tables and different bits from the key. The output of the DES function appears so unrelated to the input that the function is sometimes used as a random number generator. FIPS Pub 81 describes four modes of operation for DES and their use.

\section{Advantages}

- DES is the most widely used encryption method and is generally regarded as secure for sensitive (not classified) data applications.

\section{Disadvantages}

- DES protection is not sufficient for classified data applications.

\section{Recommended Usage}

DES is a mature and strategic technology standard and is an appropriate tool for use any time sensitive (non-classified) data encryption is required.

\section{Related Technology Standards}

Kerberos

\section{Support Contact}

IRM, Advanced Technology and Architecture Section 
Computing Standards and Guldellnes Reference

Technology Standards
Document: WSRC.1M.92.23

Section:

Page:

Issue Date:

Revision:

2 of 2

$4 / 1 / 92$

References

ANSI X3.92-1981/R1987, Data Encryption Algorithm

FIPS Pub 46, Data Encrypion Standard (DES)

FIPS Pub 81, Dara Encrypion Standard (DES) Modes of Operation 


\title{
DAL
}

\section{Associated Technology Group}

\author{
Data Management Services Services \\ Distributed Data Services
}

\section{Description}

Data Access Language (DAL, formerly called CL/1) is an application programming interface (APD) definition that allows the development of client-server applications using a variety of "front-end" clients against a variety of independent software vendors' relational database management systems (RDBMS) running on a variety of computer platforms.

Each server system contains a DAL server component that receives requests for data access in the DAL format and converts these requests into RDBMS-specific data access calls. All major RBDMS vendors are supported on IBM and DEC computers, as well as on UNIX platforms from a variety of vendors. Client applications exist for MS-DOS, OS/2, Macintosh, and UNIX operating systems. A variety of network transports support DAL, including Apple'Talk, TCP/IP, DECnet, and SNA.

\section{Advantages}

- DAL is suppurted by Apple Computer and other vendors on a variety of client and server platforms.

\section{Disadvantages}

- DAL specifications are controlled by one vendor.

- It is likely to be supplanted by RDA.

- DAL is not implemented on all computer platforns or network protocols.

- Additional processing overhead is required as compared to direct RDBMS calls.

\section{Recommended Usage}

This product, though mature, is not strategic for long term use at SRS, as its capabilities will be duplicated by the ISO standard, Remote Data Access (RDA). However, DAL today remains a useful tool for client-server computing in a heterogeneous environment.

\section{Related Technology Standards}

RDA

Support Contact

IRM, Information Systems Engineering Section

\section{References}




\section{Data Interchange Services Technology Group}

Description

Data interchange services provide specialized support for the interchange of data between applications. Areas of data interchange services include:

Document services, which include the specifications for encoding data (e.g., text, pictures, numerics, etc.) and the structure of electronic documents.

Graphics data services, which include device (hardware) independent descriptions of picture eiements.

Product data interchange services, which encompass those spocifications that describe technical drawings, documentation, and other data required for product design and manufacturing.

Messaging services, which include the descriptions of electronic mail message formats, their network envelopes and exchange protocols, and the directory services used to support message exchange.

Technology Standards

$\begin{array}{ll}\text { T5.1 } & \text { ODA/ODIF } \\ \text { T5.2 } & \text { SGML } \\ \text { T5.3 } & \text { CCITT III and IV } \\ \text { T5.4 } & \text { TIFF } \\ \text { T5.5 } & \text { CGM } \\ \text { T5.6 } & \text { IGES } \\ \text { T5.7 } & \text { EDI } \\ \text { T5.8 } & \text { RTF } \\ \text { T5.9 } & \text { Postscript } \\ \text { T5.10 } & \text { X.400 } \\ \text { T5.11 } & \text { X.500 } \\ \text { T5.12 } & \text { ASCII }\end{array}$

\section{Related Technology Standards}

\section{T8.1 CD-ROM}




\section{ODA/ODIF}

\section{Associated Technology Group}

Data Interchange Services

Document Services

Description

\section{Recommended Usage}

Office Document Archilecture / Office Document Interchange Format (ODA/ODIF) is the ISO standard that describes the document interchange format that assures receipt of a file which maintains the originator's intent with regard to formatting and presentation while maintaining the ability for the document to undergo further revisions. The multipart Office Document Architecture standard was developed in Europe in the 1980s by ISO, CCITT, and the European Computer Manufacturers Association (ECMA) for the processing and interchange of formatted documents typical in an office envirnment. The various parts of the standard define document structures, content structures, and the Office Document Interchange Format. The different data types coexist within the document. A major emphasis in ODA/ODIF is to facilitate transmission of the file to another user and to maintain document formatting and appearance just as the originator intended.

\section{Advantages}

- It preserves original document formatting and layout.

- The exchange format is application independent.

- ODA/ODIF will oullive the current proprietary word processing approaches.

- It enriches the usefulness of a document beyond creation and revision.

\section{Disadvantages}

- ODA/ODIF assumes the existence of a homogeneous document processing infrastructure.

- There are few commercially available packages that adhere to ODA formats.

- File format is limited to predetermined types of document components (e.g., vector, raster, text).

ODA is a strategic but not yet mature technology standard. It is useful for the creation and interchange of documents whose content will be further used in other document processing applications or documents whose components may have usefulness in other applications such as database, content-based retrieval, and infobases. ODA will be required in Version 2 GOSIP.

\section{Related Technology Standards}

SGML 
Computing Standards and Guldellnes Reference

Technology Standards
Document:

Section:

Page:

Issue Date:

Revision:
WSRC-IM-92-23

T5.1

2 of 2

$4 / 1 / 92$

Support Contact

IRM, Advanced Technology and Architecture Section

References

ISO 8613, Text and Office Systems-Office Document Architeciure (ODA) and Interchange Format (Parts 1-8) 


\title{
SGML
}

\section{Associated Technology Group}

\author{
Data Interchange Services \\ Document Services
}

\section{Description}

Standard Generalized Markup Language (SGML) provides generic tagging of documents and management of pointers to external non-text files. After nearly a decade of work, ANSI and ISO issuct the Sitandard Generalized Markup Language as ISO 8879:1986. SGML utilizes generic tagging of text and pointers to external data components (e.g., graphics), coupled with accompanying document type definition (DTD) files which describe the layout and format of the final form document. A DTD for any type of document may be written, and a different DTD applied to the same document will produce a different output without the need to alter the SGML file whatsoever.

\section{Advantages}

- SGML was created for structured documents; it provides a structured tagging of every element of every document.

- $\quad$ Non-text parts of the documents utilize standard formats.

- Documents are easily transmitted between applications and platforms.

- Recipients may apply the originator's or their own formatting rules, and create output in the preferred style.

- SGML will outlive the current proprietary word processing approaches.

- It enriches the usefulness of a document beyond creation and revision.

\section{Disadvantages}

- Document Type Definitions (DTDs) are difficult to write.

- Few commercially available packages adhere to SGML formats.

- Recipients are required to have an application that can open all the possible data types within a document.

\section{Recommended Usage}

SGML is both mature and strategic. It is useful for the creation and interchange of documents whose content will be further used in other document processing applications or documents whose components may have usefulness in other applications such as database, content-based retrieval, and infobases. Its focus is on cl.usses of documents that adhere to a predetermined stucture.

In 1989, a Federal Information Processing Standard (FIPS Pub 152) required that all federal agencies specify ISO 8879 in text-processing procurements.

DOE's Office of Scientific and Technical Information (OSTI) requires that electronic documents be transinitted as SGML by 1993. 
Related Technology Standards

ODA

DoD CALS utilizes SGML, as the document interchange format.

Support Contact

IRM, Advanced Technology and Architecture Section

References

ISO 8879-1986, Standard Generalized Markup Language (SGML)

FIPS Pub 152, Standard Generalized Markup Language (SGML) 
CCITT III and IV

\section{Associated Technology Group}

Data Interchange Services

Graphics Data Services

Description

CCITT Group III and Group IV compression standards define the file format and compression schemes for describing a bitonal bitmap image file for disk storage or transmission across telecommunications networks. By describing a page as a series of zeroes and ones, the black or white state of a particular spec on a page can be defined. This method is used in image scanners and FAX machines. The CCITT standard describes the method by which the redundant patterns of zeroes and ones are compressed to reduce data storage and transmission requirements.

CCITT Group III compression occurs by storing the mode ( 0 or 1$)$ and length of "runs" on a scanned line. (e.g., 136 white dots are stored as "136(0)" rather than a series of 136 consecutive zeroes)*. CCITT Group IV compression first uses the Group III scheme, and then differences each line from the one prior to it. Group IV compression typically achieves a 20:1 compression ration for a typed page.

* This is not the actual syntax but is used to demonstrate the concept of runcode words.

\section{Advantages}

- CCITT compression reduces file storage and transfer requirements for bitmap images.

- The standard is in widespread use in FAX machines, scanners, and applications.

\section{Disadvantages}

- Compression and decompression require computing resources.

- Grayscale files cannot be compressed or stored with this format.

- $\quad$ Files with few runs of black or white can cause larger file sizes than decompressed files.

- The standard does not completely describe the file format; focus is on the compression scheme. 


\section{Recommended Usage}

This standard is a mature technology and should be specified wherever possible in association with scanners, publishing systems, and image storage and retrieval systems to assure the interchange of image file data.

Related Technology Standards

TIFF

Support Contact

IRM, Advanced Technology and Architecture Section

References

"Standardization of Group 3 Facsimile Apparatus for Document Transmission," Recommendation T.4, Volume VII, Facsimile VII.3, CCITT, Geneva, 1985

"Facsimile Coding Schemes and Coding Control Functions for Group 4 Facsimile Apparatus," Recommendation T.6, Volume VII, Facsimile VII.3, CCITT, Geneva, 1985 


\section{TIFF}

\section{Associated Technology Group}

Data Interchange Services

Graphics Services

Description

Aldus and Microsoft's joint venture into a common tag image file format (TIFF), a tag based file format that is used to promote the interchange of digital image data. TIFF was designed to make life easier for scanner vendors, desktop publishing software developers, and users of these two classes of products, by reducing the proliferation of proprietary scanned image formats. It is not a printer or page description language and is not intended to be a general document interchange standard.

\section{Advantages}

- TIFF allows pictures to be exchanged between IBM and Macintosh PCs.

- It is designed for future growth by including a tag to each field, thus allowing creation of new field types without invalidating the existing types.

- TIFF works with bilevel, grayscale, palette, and RGB type images.

- Three different compression schemes are implemented, saving disk space.

\section{Disadvantages}

- Some existing software cannot translate into or out of TIFF.

\section{Recommended Usage}

TIFF is a mature standard and is recommended for desktop publishing requiring inclusion of scanned images.

\section{Related Technology Standards}

\section{None}

Support Contact

IRM, Advanced Technology and Architecture Section

References

Tag Image File Format Specification Revision 5.0, Aldus Corporation 
CGM

Associated Technology Group

Data Interchange Services

Graphics Data Services

Description

Computer Graphics Metafile (CGM) is an ANSI standard that defines how 2-D vector illustrations are to be encoded to transfer into and between technical publications packages. It supports lines, fill areas, polygons, and text graphics primitives. It is a metafile format that incorporates bitumapped and vector graphics. Many vendors of document publishing applications support CGM translators for import or export of graphics data into or from their applications.

\section{Advantages}

- CGM was conceived as the common public format for interchange of graphics files.

- Definition of illustrations through use of primitives simplifies the file itself and makes it easily transportable.

\section{Disadvantages}

- Many applications that are CGM-compliant do not support the full range of CGM features.

- $\quad$ Full-featured CGM generators and filters are not widely available.

- Many vendors are producing proprietary extensions to the CGM definition without ANSI approval.

- The standard has not been updated since 1986.

Recommended Usage

CGM is a mature technology standard and is recommended for specifications that will require some level of file interchange with yet-to-be specified products. Many product taanslators provide direst translations to other products with a higher degree of accuracy than that obrainable with CGM.

\section{Related Technology Standards}

None 
Computing Standards and Guldelines Feference

Document: WSRC-IM-92.23

Section:

T5.5

Page:

Issue Date:

2 of 2

Technology Standards

Revision:

$4 / 1 / 92$

Support Contact

IRM, Advanced Technology and Architecture Section

References

ANSI X3.122-1986, Computer Graphics Metafile for the Storage and Transfer of Picture Description Information

FIPS Pub 128, Computer Graphics Metafile (CGM) 


\section{IGES}

\section{Associated Technology Group}

Data Interchange Services Graphics Data Services

\section{Description}

Initial Graphics Exchange Specification (IGES) is an ANSI standard for vector-graphic data representation that allows different Computer Aided Design / Computer Aided Manufacturing (CAD/CAM) systems to interchange product-definition data in an ASCII format. It defines hundreds of entity types, including circles, arcs, vectors, text, and the like, for rendering of mechanical drawings and technical illustrations. IGES is expected to be superseded by the Standard for The Exchange of Product Model Data (STEP).

\section{Advantages}

- IGES is robust enough to accommodate almost any CAD feature.

- A subset of the IGES standard is in widespread use in the DoD CALS program.

- Some IGES translators between specific products produce high quality results.

\section{Disadvantages}

- The large number of features defined by the standard makes a complete implementation nearly impossible.

- Use of translators requires some tailoring to assure entity type matching.

- Text handling is weak with respect to fonts and sizing.

\section{Recommended Usage}

IGES is a mature technology standard and is recommended for specifications that will require some level of CAD/CAM file interchange with yet-to-be specified products. Many product translators provide direct translations to other products with a higher degree of accuracy than does IGES.

\section{Related Technology Standards}

None

Support Contact

IRM, Advanced Technology and Architecture Section

\section{References}




\section{EDI}

\section{Associated Technology Group}

Data Interchange Services

Messaging Services

\section{Description}

Electronic Data Interchange (EDI) is the computer-to-computer interchange between companies and organizations of data contained in common business cocuments in computer-readable form under strictly defined standards. The EDI staridard defines the way the documents are formatted, the information the documents contain, and mechanisms for determining whether the document should be transmitted. The standard has two parts: ANSI X12 for domestic transactions, and EDIFACT for international transactions. X12 and EDIFACT are not compatible.

\section{Advantages}

- $\quad$ EDI will allow electronic transactions for RFQ, purchasing, and other financial information.

- $90 \%$ cust za: ings are possible in the issuance of Electronic Funds Transfers over checks.

- EDI allows online access by vendors to RFQs rather than the mailing of printed copies.

\section{Disadvantages}

- Integration of EDI into existing applications could be expensive.

- Security aspects of EDI (e.g., electronic check payments) are uncertain.

- EDI and EDIFACT are not compatible, yet both are in the FIPS.

\section{Recommended Usage}

EDI is a mature and a strategic technology standard. It should be considered for purchasing systems that wish to conduct financial transactions or to distribute bid information electronically to potential vendors or suppliers.

In 1991, the Federal Information Processing Standard (FIPS Pub 161) required that all federal agencies specify X12 and EDIFACT in all EDI systems by 1996.

\section{Related Technology Standards}

None

\section{Support Contact}

IRM, Informati in Systems Engineering Section 
Computing Standards and Guldellnes Reference

Document:

Section:

Page:

Issue Date:

Technology Standards

Revision:

WSRC-IM-92-23

T5.7

2 of 2

$4 / 1 / 92$

References

ANSI ASC X12D/90-382, EDI Implementation Reference Manual Guidelines

FIPS Pub 161, Electronic Data Interchange 


\section{RTF}

\section{Associated Technology Group}

Data Interchange Services

Document Services

Description

Rich Text Format (RTF) is the Microsoft word processing interchange format for describing text, formatting, and imbedded graphics exchanged with other applications and word processing packages. RTF uses encoding to produce an ASCII file that completely describes the document content and format. Many word processing packages and desktop publishing applications from a wide variety of vendors can read RTF.

\section{Advantages}

- $\quad$ RTF is a widely used and simple to invoke document interchange format.

- $\quad$ RTF files are structured in a manner that can be parsed so that the content information can be used by other applications.

\section{Disadvantages}

- RTF layout is limited to word processing layout capabilities; it cannot accommodate desktop publishing layouts.

- RTF is limited to the capabilities of Microsoft word processing packages, and

might not transmit or accept a more robust format with another package.

- Although possible, few non-word processing applications (e.g., databases, spreadsheets) use RTF for text imports.

\section{Recommended Usage}

RTF is a mature but nonstrategic technology standard. It is the most common interchange format for Macintosh and PS/2 word processing applications. It should be used as the intermediate format for documents exchanged between applications or platforms (unless the capability exists to read another's native file format). In the future, ODA/ODIF will replace RTF for the exchange of word processing files.

\section{Related Technology Standards}

ASCII

ODA/ODIF

\section{Support Contact}

IRM, Advanced, Technology and Architecture Section

References 


\section{Postscript}

\section{Associated Technology Group}

Data Interchange Services

\section{Description}

Postscript is a programming language popularized by Adobe Systems Inc. and adopted throughout the computer industry as a standard that allows for the description of pages for printing. The controller for interpreting the language resides in the hardware or firmware of the printer. It describes arbitrary shapes, geometric primitives, and painting (raster) primitives, and fully integrates text (as graphical shapes) from a wide variety of fonts. The Postscript file format (the output from a generator) can be manipulated, modified, or stored. Recent additions include color support and display Postscript (for non-printer output). Most instances of Postscript in files are actually Encapsulated Postscript (EPS). EPS is an almost complete subset of Postscript in which has some of the timeconsuming or complex Postscript commands have been removed. EPS also includes the addition of a header definition which provides additional physical page size definitions and identifies the file as EPS. EPS is the form of a Postscript file that is typically achieved via "Save As Postscript" or "Print to Postscript" commands, or interchanged between computers (and sometimes to printers).

\section{Advantages}

- Postscript is widely used and supported by virtually every laser printer manufacturer.

- It is robust and extensible enough to handle any printing requirement.

- $\quad$ Postscript has remained stable since 1986.

\section{Disadvantages}

- Postscript is very verbose, especially in its description of raster files.

- Not all personal computer application programs support output to Postscript.

\section{Recommended Usage}

Postscript is a mature technology standard. Postscript printers are the de facto standard for desktop workstations and many laser printers. Its use as a data file interchange format is untested in most applications areas.

\section{Related Technology Standards}

None

\section{Support Contact}

IRM, Advanced Technology and Architecture Section 
Computing Standards and Guldelines Reference

Technology Standards
Document:

Soction:

Page:

Issue Date:

Revision:
WSRC-IM-92-23

T5.9

2 of 2

$4 / 1 / 92$

References

Postscript Language Reference Manual, Adobe Systems, Inc., 1985 


\section{Associated Technology Group}

Data Interchange Services

Messaging Services

\section{Description}

$\mathrm{X} .400$ is the standard defined by the International Telegraph and Telephone Consultive Committee (CCITT) and adopted by the International Standards Organization to define electronic message format and the protocol for exchanging electronic messages across a network. Under X.400, the user applications, called User Agents (UA), exchange messages with an electronic post office, called a Message Transfer Agent (MTA). X.400 defines the protocol used between UA and MTA, as well as between multiple MTAs. A set of interconnected MTAs comprise a Message Transfer System. MTAs plus UAs make up a Message Handling System (MHS). A principal feature of the MHS is that it operates in a store and forward manner. Heterogeneous electronic mail system can be linked together, if each supports the X.400 protocol for connecting MTAs.

X.400 mail exchange rests on top of an OSI protocol network. Long term direction for electronic mail requires integrated directory services based upon the X.500 standard.

Current GOSIP rules require the 1984 version of the standard, but later GOSIP versions will require that the X.400 Version 1988 be supported.

\section{Advantages}

- X.400 is a GOSIP standard so that all mail vendors do or will support X.400.

- Document content is not limited to text messages but can support arbitrary binary file transfers.

\section{Disadvantages}

- X.400 requires OSI network protocols.

- Effective use of X.400 requires Directory Services.

- There is limited use of X.400 except for public mail systems.

Recommended Usage

X.400 is a mature and strategic technology standard. GOSIP requires that all new electronic messaging systems procured for the U. S. Government (including SRS) support the X.400 messaging standard. In practice, X.400 will be used to link heterogeneous electronic mail systems. 
Computing Standards and Guldellnes Reference

Technology Standards
Document: Section:

Page:

Issue Date:

Revision:
WSRC-IM-92-23

T5.10

2 of 2

$4 / 1 / 92$

Related Technology Standards

OSI

X.500

Support Contact

IRM, Computer and Telecommunications Management Section

References

CCITT 1988 Recommendation X.400, Message Handling: System and Service Overview 


$\begin{array}{llr}\text { Computing Standards and Guldellnes Reference } & \text { Document: } & \text { WSRC-IM-92-23 } \\ & \text { Sectlon: } & T 5.11 \\ & \text { Page: } & 1 \text { of } 2 \\ \text { Issue Date: } & 4 / 1 / 92 \\ \text { Technology Standards } & \text { Revislon: } & 0\end{array}$

$X .500$

Associated Technology Group

Data Interchange Services

Messaging Services

Description

X.500 is an evolving joint standard of the Consultative Committee for International Telegraphy and Telephony (CCITT) and the International Standards Organization (ISO), and specifies how directory systems exchange information on a worldwide scale. X.500 services are to be closely integrated into X.400 message handling systems.

X.500 consists of two main components. The Directory User Agent (DUA) represents the user and provides a portal into the directory. The Directory System Agents (DSAs) are servers that each implement a portion of the directory.

The OSI model contains only one globally distributed hierarchical directory with an integrated, unified naming space. Every entity or object stored in the directory has a globally unique name. The directory is distributed over a collection of DSAs.

The most important parts of X.500 to be completed for a 1992 draft are replication and access control, which are essential for the commercial deployment of X.500.

\section{Advantages}

- $\quad$ X.500 is a future GOSIP requirement.

- It allows global directories for large interconnected enterprises.

Disadvantages

- Final version of the standard is not yet complete.

- There are no commercially available implementations.

\section{Recommended Usage}

$\mathrm{X} .500$ is a strategic technology standard for the future. Vendors should be requested to provide X.500-compliant products, but proprietary directory services will still be required for the next few years. 
Related Technology Standards

OSI

$\mathrm{X} .400$

Support Contact

IRM, Computer and Telecommunications Management Section

References

CCITT 1988 Recommendation X.500, The Directory-Overview of Concepts, Models, and Service 


\section{ASCII}

\section{Associated Technology Group}

Data Interchange Services

Document Services

\section{Description}

The American Standard Code for Information Interchange (ASCII) is the industry standard for the binary encoding and exchange of alphanumeric text. This standard uses 7 bits to encode 128 possible characters, including upper and lower case letters, the 10 numerals, punctuation characters, and a few special control characters.

Because ASCII is limited to a character set of 128 possible values, it is not suitable for the exchange of fully revisable word processing files. Nevertheless, word processing files are often converted to ASCII and exchanged between computer systems. When this is done, special formatting features such as bold text, headers, and superscripts are not preserved but must be recreated manually on the receiving system.

\section{Advantages}

- $\quad$ ASCII is a very mature standard supported by all computer vendors.

\section{Disadvantages}

- It is suitable for only alphanumeric text exchange.

- Computer word processing files contain many formatting codes that cannot be preserved under an ASCII text exchange.

\section{Recommended Usage}

ASCII is a mature technology standard which should be used as a lowest common denominator for exchange of alphanumeric text data.

\section{Related Technology Standards}

None

\section{Support Contact}

IRM, Computer and Telecommunications Management Section 
ComputIng Standards and Guldellnes Reference

Technology Standards
Document: Section:

Page:

Issue Date:

Revision:
WSRC-IM-92-23

T5.12

2 of 2

$4 / 1 / 92$

References

FIPS Pub 1-2, Code for Information Interchange, Its Representation, Subsets, and Extensions

ANSI X3.4-1986, Code for Information Interchange 


\section{Graphics Services Technology Group}

Description

Graphics services provide functions for creating and manipulating pictures. These services include display element definition and management, and graphical object attribute definition and management. These services are defined in specifications for describing multi-dimensional graphic objects in a form that is independent of output devices and managing hierarchical database structures containing graphics.

Technology Standards

$\begin{array}{ll}\text { T6.1 } & \text { GKS } \\ \text { T6.2 } & \text { PHIGS }\end{array}$

Related Technology Standards

T2.3 PEX

T5.9 Postscript 


$\begin{array}{llr}\text { Computing Standards and Guidelines Reference } & \text { Document: } & \text { WSRC-IM-92.23 } \\ & \text { Sectlon: } & \text { T6.1 } \\ & \text { Page: } & 1 \text { of } 1 \\ \text { Issue Date: } & 4 / 1 / 92 \\ \text { Technology Standards } & \text { Revislon: } & 0\end{array}$

\section{GKS}

Associated Technology Group

Graphics Services

\section{Description}

Graphical Kemel System (GKS) defines an applications programming interface for applications that produce computer generated two dimensional (2-D) pictures on vector or raster graphics output devices. GKS provides constructs and subroutine library calls for virtually any kind of 2-D graphic image. GKS includes program interface bindings for Ada, Pascal, and FORTRAN.

GKS functions include output of graphics primitives, obtaining graphics input, manipulating graphics metafiles, enror handling, generating and control of segments, controlling graphics workstations, and controlling of coordinate systems and transformations.

\section{Advantages}

- $\quad$ GKS is a mature 2-D graphics programming interfare standard.

- It is graphics device independence.

- It has good vendor support.

\section{Disadvantages}

- GKS provides 2-D graphics only.

\section{Recornmended Usage}

GKS is a mature technology standard and should be used for developing 2-D graphics applications where device independence and/or program portability are desired.

\section{Related Technology Standards}

PHIGS

Support Contact

IRM, Advanced Technology and Architecture Section

\section{References}

ANSI X3.124-1985, Graphic Kernel System

FIPS Pub 120-1, Graphical Kernel System (GKS) 


\section{PHIGS}

\section{Associated Technology Group}

Graphics Services

Description

Programmer's Hierarchical Interactive Graphics System (PHIGS) provides a functional interface between an application program and a configuration of graphical input and output devices. The functional interface contains basic functions for dynamic interactive hierarchical graphics on a wide variety of graphic equipment. The set of functions includes:

- definition, display, and modification of 2-D or 3-D graphical data

- definition, display, and modification of geometrically related objects

- modification of graphical data and the relationships between the graphical data

PHIGS implementations provide for graphics device independence and program portability by providing the programmer a standard subroutine library for 3-D graphics functions. In addition to providing the functionality of earlier graphical standards (GKS and GKS-3), this standard enables graphical (and application) data to be stored in a hierarchical data store. This standard is aimed for an environment requiring a high degree of interactivity, and it extends the GKS concept of the workstation to support a dynamic environment.

PHIGS is definel by ANSI and adopted by ISO as a standard. Language bindings are complete for Ada and FORTRAN, and planned for C and Pascal. A new standard, called PHIGS Plus, is being developed to add shading, lighting, and other advanced graphics programming capabilities not included in PHIGS.

\section{Advantages}

- PHIGS supports 3-D as well as 2-D graphics.

- There is good vendor support.

\section{Disadvantages}

- $\quad$ language binding has not yet been completed.

\section{Recommended Usage}

PHIGS is a strategic but not yet mature technology. Where implementations are available, it should be used for developing graphics applications where device independence and/or program portability are desired. 
Related Technology Standards

GKS

PEX

Support Contact

IRM, Advanced Technology and Architecture Section

References

ANSI X3.144-1988 and ANSI X3.144.1-1988, Computer Graphics-Programmer's Hierarchical Interactive Graphics System (PHIGS) Functional Description

FIPS Pub 153, Programmer's Hierarchical Interactive Graphics System (PHIGS) 


\section{Network Services Technology Group}

Description

Network Services provide the functions to support the connections of workstations (terminals or personal computers) to host computer-based applications, the transfer of information across a heterogeneous computing environment, the sharing of computer resources such as disk drives and printers across a network, and distributed applications requiring data access across a heterogeneous computer network.

Technology standards for Network Services fall into the following categories:

Physical and data link level protocols represent the lowest level network protocols that describe the hardware and the basic transmission of bits of information.

Communications protocols are the rules that describe how data messages are transferred across a network, how the data is interpreted, and what basic application functionality is provided by the network.

Network security services include access, authentication, confidentiality, and integrity controls in the management of communications between senders and receivers of information in a network.

\section{Technology Standards}

$\begin{array}{ll}\text { T7.1 } & \text { Ethernet } \\ \text { T7.2 } & \text { Token Ring } \\ \text { T7.3 } & \text { FDDI } \\ \text { T7.4 } & \text { OSI } \\ \text { T7.5 } & \text { TCP/IP } \\ \text { T7.6 } & \text { DECnet / LAT } \\ \text { T7.7 } & \text { SNA } \\ \text { T7.8 } & \text { XNS/IPX } \\ \text { T7.9 } & \text { AppleTalk } \\ \text { T7.10 } & \text { SNMP } \\ \text { T7.11 } & \text { Kerberos }\end{array}$

Related Technology Standards

$\begin{array}{ll}\text { T8.2 } & \text { RS-232 } \\ \text { T8.3 } & \text { RS-449/RS-442/RS-423 } \\ \text { T8.4 } & \text { V.35 }\end{array}$




\begin{tabular}{llr} 
Computing Standards and Guldellnes Reference & Document: & WSRC-IM-92-23 \\
& Sectlon: & Page: \\
& Issue Date: & 17.1 \\
Technology Standards & Revislon: & $4 / 1 / 92$ \\
& & 0 \\
\hline
\end{tabular}

\title{
Ethernet
}

\section{Associated Technology Group}

\author{
Network Services \\ Physical and Data Link Level Networking
}

\section{Description}

Ethernet (IEEE 802.3) is the LAN standard for shared media access with the widest vendor implementation support. Ethernet is an earlier standard developed jointly by DEC, Intel, and Xerox based on earlier Xerox research and is the standard upon which IEEE 802.3 is based. Version 2 of the Ethernet standard and IEEE 802.3 differ in small details, but products based on the two standards can coexist on a single LAN. Ethernet is implemented using $50 \mathrm{ohm}$ coaxial cable (thick = RG8, thin=RG58) as well as fiber optic (62.5 micron multimode fiber) cables. The IEEE has also endorsed a new standard, called 10Base T, for IEEE 802.3 or Ethemet use of unshielded twisted pair (UTP) cables. Newer site implementations are based on fiber optic cables linking buildings within an area and 10Base $T$ implementations within the buildings.

The basic data rate of Ethernet over all wiring schemes is 10 million bits per second (mbps). With coax cable, Ethernet end-to-end distances are limited to 1600 meters; fiber optic cables and repeaters extend this to 2800 meters; and network bridges extend a single physical network up to 28,000 meters. 10BaseT requires that Ethernet devices be located within 100 meters of a central wiring room. Each SRS area can be (and generally is) covered by an Ethernet LAN. Etherret uses a time-shared bus technology that resolves multiuser contention for access to transmission on the cable with a fast yet simple algorithm called CSMA-CD. This technique is very fast and efficient at low levels of network use and can support overall network loading of about 70-80\% of the basic transmission rate.

\section{Advantages}

- A very large installed base of products support Ethernet.

- $\quad$ Ethernet operates on coax, fiber optic, and twisted pair cables.

- It provides for simple installations with no tuning requirements.

\section{Disadvantages}

- Maximun clata rate of 10 mbps is in danger of being exceeded by fast workstations.

- There is no priority mechanism for guaranteed network access under heavy loads.

\section{Recommended Usage}

Ethernet (IEEE 802.3) is a mature and strategic technology standard and is the primary site LAN standard. Its use is recornmended for all site L.ANs except where special requirernents dictate FDDI or 'Token Ring. 
Related Standards

Token Ring

FDDI

Support Contact

IRM, Computer and Telecommunications Management Section

References

ANSI/IEEE Standard 802.3-1985, CSMA-CD Access Method and Physical Layer Specification

FIPS Pub 107, Local Area Networks: Baseband Carrier Sense Multiple Access with Collision Detection Access Method and Physical Layer Specifications and Link Layer Protocol

ISO/DIS 8802/3, Local Area Networks-Part 3: Carrier Sense Multiple Access with Collision Detection 


\title{
Token Ring
}

\section{Associated Technology Group}

\author{
Network Services \\ Physical and Data Link Level Networking
}

\section{Description}

Token Ring is a physical and link level LAN specification. It has been defined by IBM and adopted by ANSI, IEEE, and ISO. ANSI/IEEE 802.5-1985 specifies the formats and protocols used by the token-passing nnedium access control sublayer, the physical layer, and the means of attachment to the toiken-passing ring medium. Token Ring is IBM's strategic direction for local area networks. It is particularly well supported by IBM for IBM Personal Computers and PS/2 connectivity in work group and IBM host interface applications. Token Ring utilizes unshielded twisted pair, shielded twisted yairs, or fiber optic cables at the basic data rate of 4 megabits per second (mbps). Newer products support $16 \mathrm{mbps}$ as well as the slower rate. IBM's 16 mbps products also support 4 mbps, but a single ring may only run at one speed. Token Rings can be extended by using local or remote bridges so that several rings can be combined into one internetwork.

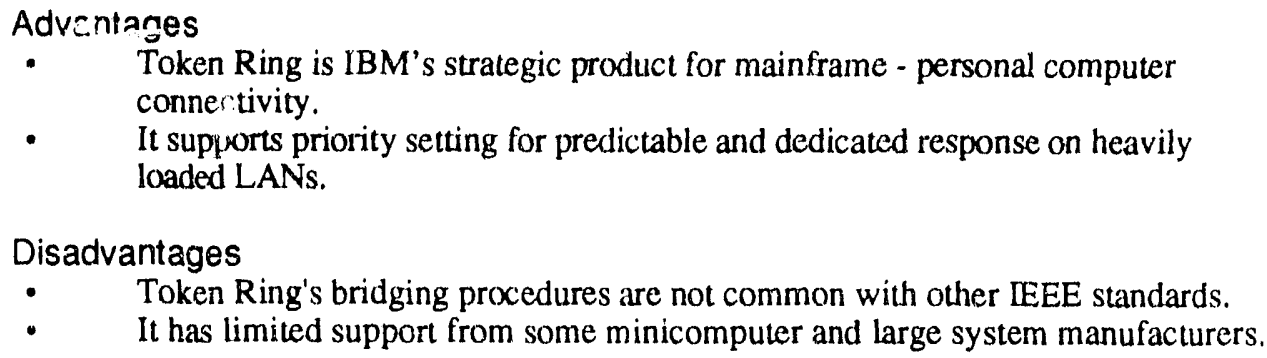

\section{Recommended Usage}

Token Ring is a mature technology standard but is not strategic for site use. Ethernet (IEEE802.3) is the primary site LAN standard. Token Ring is supported as an alternative for special requirements.Upper level protocols SNA, TCP/IP, and IPX have been supported on the site over a Token Ring LAN.

\section{Related Standards}

\section{Ethernet \\ FDDI}


Computing Standards and Guldelines Reference

Document:

WSRC-1M-92-23

Section:

T7.2

Page:

Issue Date:

2 of 2

Technology Standards

Revision:

Support Contact

IRM, Computer and Telecommunications Management Section

References

ANSI/IEEE Standard 802.5-1985, Token Ring Access Method and Physical Layer Specifications

ISO 8802/5, Local Area Networks Part 5: Token Ring Access Method and Physical Layer Specifications 
FDDI

Associated Technology Group

Network Services

Physical and Data Link Level Networking

Description

Fiber Distributed Data Interface (FDDI) is an ANSI and ISO standard LAN technology developed to provide an order of magnitude improvement in speed over existing LAN technologies. FDDI is based on fiber optics communication using a form of token passing protocol for station access at speeds of 100 million bits per second. FDDI supports distances of up to 2 kilometers between stations in a standard configuration with extensions of up to 25 kilometers between stations with special optics (lasers and single mode fiber).

FDDI is supported by all major communications and computer system vendors.

Equipment is being produced to allow the attachment of systems to an FDDI LAN and to use an FDDI LAN to interconnect Ethernet and/or Token Ring LANs together. The site LAN currently uses FDDI to link the IBM and Cray mainframe computers together and will be extended with further FDDI trunks in the future.

The FDDI standard is subdivided into four parts:

PHY - Physical Protocol

PMD - Physical Medium Dependent Protocol

MAC - Medium Access Control Protocol

SMT - Station Management Protocol

The U.S. Government OSI profile (GOSIP) Version 3 will sanction FDDI as an option to Fthernet or Token Ring for LAN implementations.

\section{Advantages}

- FDDI is the only standard for high performance (greater than 16 mbps) L.ANs.

- All major computer vendors support FDDI.

- It provides fault tolerant features.

\section{Disadvantages}

- FDDI interfaces are relatively expensive.

- No FDDI adapters are available for PS/2 or Macintosh personal computers.

- The station management protocol has not yet been finalized.

\section{Recommended Usage}

FDDI is a strategic technology standard but is not yet mature. Ethernet (IEEE802.3) is the primary site LAN standard. FDDI is supported as an altemative for special requirements. 
Related Standards

Ethernet

Token Ring

OSI

Support Contact

IRM, Computer and Telecommunications Management Section

References

ANSI X3.139-1987, Fiber Distributed Data Interface (FDDI) Token Ring Media Access Control (MAC)

ANSI X3.148-1988, Fiber Distributed Data Interface (FDDI) Physical Layer Protocol (PHY)

ANSI X3.166-1990, Fiber Distributed Data Interface (FDDI) Physical Layer Medium Dependent (PMD)

ANSI X3T9.5, Fiber Distributed Data Interface (FDDI) Station Management Protocol (SMT) (Draft) 


\section{OSI}

\section{Associated Technology Group}

Network Services

Communications Protocols

Description

Open Systems Interconnect (OSI) is a set of communications standards sponsored by the International Standards Organization (ISO) to facilitate the construction of open, heterogeneous computer networks. OSI protocols have been endorsed by the U. S. government. Government (including SRS) procurements for communicating computers must specify a subset of OSI protocols in the functional specifications for the systems. This is referred to as the GOSIP (Government OSI Protocols) requirement.

OSI is a feature rich, multiple-layered protocol family. OSI networks will use IEEE 802 (Ethernet and Token Ring), FDDI LANs, point-to-point links, or X.25 packet switch networks to provide standard applications such as virtual terminal (VTP), file copy (FTAM), and electronic messaging (X.400). Eventually, OSI protocols will replace TCP/IP and many of the proprietary network protocols in use at SRS, but OSI implementations are still immature.

\section{Advantages}

- $\quad$ OSI is an emerging international standard to be supported by all major computer vendors.

\section{Disadvantages}

- $\quad$ OSI products are immature and not widely available as yet.

\section{Recommended Usage}

OSI is a strategic but not yet mature technology standard. Today, certain parts of the OSI standards are more mature than others. OSI rests on existing LAN technologies in use at SRS. X.400 is the only standard for linkage of electronic messaging systems. Other OSI applications remain incomplete.

Related Standards

X.400

X.500

Ethernet

Token Ring

FDDI 
Computing Standards and Guldellnes Reference

Document:

Sectlon:

Page:

Issue Date:

Revision:

WSRC-1M-92-23

T7.4

2 of 2

Technology Standards

$4 / 1 / 92$

0

Support Contact

IRM, Computer and Telecommunications Management Section

References

ISO 7498-1984, Open Systems Interconnection-Basic Reference Model

FIPS Pub 146, GOSIP, Government Open Systems Interconnection Profile—Version 1

FIPS Pub 146-1, GOSIP Version 2.0 
TCP/IP

Associated Technology Group

Network Services

Communications Protocols

Description

Transmission Control Protocol / Internet Protocol (TCP/IP) is a family of communications protocols designed to support communications between heterogeneous computers. As such, it is now viewed as a precursor to OSI networking. Functions provided by TCP/IP include file transfer (FTP), electronic mail (SMTP), and support for terminal login across the network (TELNET). TCP/IP has been implemented to utilize most LAN physical and link level protocols (such as Ethernet and Token Ring). Any TCP/IP node has a unique address and node name. Network addresses and names are administered at SRS by IRM. These addresses are consistent with the global TCP/IP addressing scheme, so that if future TCP/IP links between SRS and off-site locations are developed, the addresses will not conflict.

At SRS, TCP/IP implementations are available for UNIX systems (including the Cray), the IBM mainframes, VAX VMS systems, and personal computers (both IBM and Apple). A robust TCP/IP routing network between SRS areas and major off-site work locations is in place.

TCP/IP protocols are defined by the Internet Activities Board (IAB) series of documents called Requests For Comment (RFC).

\section{Advantages}

- There is wide support across vendor lines (including Apple, Cray, DEC, and IBM) for TCP/IP.

- $\quad$ TCP/IP is supported over all LAN types as well as wide area networks.

- Some products are available in the public domain at no cost.

Disadvantages

- $\quad$ Each TCP/IP device requires a unique, static address.

- $\quad$ TCP/IP will be replaced by OSI protocols in the next several years.

\section{Recommended Usage}

TCP/IP is a mature and strategic technology standard and is the recommended protocol for linkage of heterogeneous computer systems. In the future, OSI communications protocols will supplement and later supplant TCP/IP. 
Computing Standards and Guldelines Reference

Document:

Section:

Page:

Issue Date:

Revision:

WSRC-IM-92.23

T7.5

2 of 2

Technology Standards

$4 / 1 / 92$

Related Standards

SNMP

OSI

Support Contact

IRIM, Computer and Telecommunications Management Section

References

RFC 791, Internet Protocol

RJ:C 793, Transmission Control Protocol

RFC 854, Telnet Protocol

RFC 959, File Transfer Protocol 


\section{DECnet/LAT}

\section{Associated Technology Group}

Network Services

Communications Protocols

\section{Description}

DECnet is Digital Equipment Corporation's (DEC) implementation of DEC's proprietary Digital Network Architecture (DNA). DECnet provides a rich set of features for network communications between DEC systems. These features include virtual terminal logins, file copies, electronic mail exchange, remote file access, task-to-task communications, and network management. DECnet protocols, although proprietary to DEC, are published and have been implemented by a variety of vendors. There are DECnet implementations available for IBM mainframes (Interlink), IBM PCs, Apple Macintosh computers, and SUN workstations, to name a few.

DECnet utilizes unique addresses and names for each node on the network. Addresses are subdivided into area numbers and node numbers. IRM is responsible for managing the DECnet address assignments and has established : IECnet areas to correspond to site areas. In 1992 DEC will distribute a new version (Phase V) which will make DECnet compatible with OSI networking protocols.

LAT (Local Area Transport) is a separate DEC LAN protocol for connecting LAN terminal servers to VAX computers. LAT software is bundled into the VAX/VMS operating system, and is very efficient.

\section{Advantages}

- DECnet and LAT are mature and full featured.

- They are integrated into DEC operating systems at little or no additional cost.

Disadvantages

- DECnet/LAT are not avail’'se for as many vendors' equipment as TCP/IP.

- LAT terminal servers connect only to DEC host computers.

\section{Recommended Usage}

DECnet is a mature technology standard and is the recommended protocol for linkage of Digital Equipment Corporation (DEC) computer systems today. TCP/IP is now supplementing DECnet on many VAX systems. In the future, DEC will change DECnet, basing it on OSI protocols. LAT is the recommended protocol for linking terminal servers to VAX computer systems. It is the site's long term direction to phase out terminal servers and LAT in favor of directly connecting personal computers to the site LAN using TCP/MP or OSI prowcols. 
Computing Standards and Guldelines Reference

Technology Standards
Document:

Section:

Page:

Issue Date:

Revision:
WSRC-1M-92.23

$r 7.6$

2 of 2

$4 / 1 / 92$

Related Standards

OSI

TCP/IP

Support Contact

IRM, Computer and Telecommunications Management Section

References

DECnet DIGITAL Network Architecture (Phase IV) General Description,

Digital Equipment Corporation 


\title{
SNA
}

\section{Associated Technology Group}

\author{
Network Services \\ Communications Protocols
}

\section{Description}

IBM's Systems Network Architecture (SNA) is IBM's unifying communications architecture for linking diverse IBM products from the desktop to the largest mainframe computer systems. It predominantly follows a hierarchical model with controls established at the mainframe, but is being extended to support local area networks and peer-to-peer services. SNA defines the protocols used to support the IBM 3270 terminal system as well as computer-to-computer links. SNA provides the strategic communications component of IBM's Systems Applications Architecture (SAA), IBM's blueprint for a computer application development and delivery environment.

Key SNA protocols have been published, and other vendors often use SNA protocols for communicating to IBM systems. The term SNA Gateway is often used to mean a device that speaks both SNA and non-SNA protocols, and provides the connection for non-lBM equipment to the IBM mainframe.

\section{Advantages}

- SNA is a de facto standard endorsed by many vendors as a means of communicating with IBM central computer systems.

- It is widely used in personal computer to mainframe links and Token Ring LANmainframe connections.

\section{Disadvantages}

- SNA is proprietary to IBM.

- It requires relatively large amounts of time, skill, and resources to support.

- It is strongly hierarchical in nature and requires coordination among different nodes in the network.

\section{Recommended Usage}

SNA is a mature technology standard and is one recommended protocol for communications with the IBM mainframe in the Central Computer Facility. TCP/IP is becoming increasingly more important for non-IBM systems communications with IBM mainframes, and OSI will be so in the future. IBM will work to supplement SNA with additionaI TCP/IP and OSI capabilities.

\section{Related Standards}


Computing Standards and Guldellnes Reference

Document:

Section:

Page:

Issue Date:

To, hnology Standards

Revision:

WSRC-1M-92-23

T7.7

2 of 2

$4 / 1 / 92$

Support Contact

IRM, Computer and Telecommunications Management Section

References

IBM Systems Network Architecture Concepts and Products GC30-3073-3, IBM

Corporation 


\section{XNS/IPX}

\section{Associated Technology Group}

Network Services

Communications Protocols

\section{Description}

XNS (Xerox Network Services) is a protocol family developed by Xerox Corporation, placed in the public domain, and used (and often modified) by many computer vendors. It follows a layered model much like the OSI model.

At SRS, XNS is used by Intergraph Computer-Aided Design (CAD) systems for interprocessor communications. A modified version of XNS, IPX (Internet Packet Exchange), is the basic protocol used in Novell's Netware operating system. Because there are many different versions of XNS, interoperability between vendors' versions is not assured. TCP/IP is recommended as a more standard method available today for multivendor communications, and OSI will be recommended in the future.

\section{Advantages}

- The version to support Novell's Netware (IPX) is widely implemented.

\section{Disadvantages}

- There are many different versions of XNS that are often incompatible.

- $\quad \mathrm{XNS}$ and IPX will be replaced by TCP/P and/or OSI in the future.

\section{Recommended Usage}

This is a mature but non-strategic technology standard. At SRS, XNS support is limited to Intergraph workstations. IPX is the standard protocol for Novell Netware implementations and is supported at SRS. This protocol is expected to be replaced by $\mathrm{TCP} / \mathrm{IP}$ and/or OSI in the future.

Support Contact

IRM, Computer and Telecommunications Management Section

Related Standards

TCP/IP

OSI 
Computing Standards and Guldellnes Reference

Technology Standards
Document:

Section:

Page:

Issue Date:

Revision:
WSRC-1M-92-23

T7.8

2 of 2

$4 / 1 / 92$

0

References

Novell API Reference Manual, Volume II

Intergraph Network Core User's Guide, Document Number DSYS017 


\title{
AppleTalk
}

\section{Associated Technology Group}

\author{
Network Services \\ Communications Protocols
}

\section{Description}

AppleTalk is a family of communications protocols developed by Apple. AppleTalk is often confused with the LocalTalk physical networking standard. The AppleTalk protocol suite is full-featured, including support for datagrams (DDP), reliable data streams (ADSP), file sharing (AFP), and printing (PAP). AppleTalk has full routing capabilities for use in local and wide area applications. AppleTalk has been implemented to utilize most LAN physical and link level protocols, such as Ethernet (called EtherTalk) and Token Ring (TokenTalk), as well as Apple's LocalTalk wiring. Address assignment is done dynamically and transparently to the user.

At SRS, AppleTalk is primarily used to support work-group printers and Macintosh file servers. There are implementations available for UNIX, PC-DOS, and VMS systems that support file sharing and printing. SRS has implemented a robust AppleTalk routing network between SRS areas and off-site facilities.

Advantages

- $\quad$ AppleTalk supports all LAN types as well as wide area networks.

- Apple's LocalTalk wiring scheme and the AppleTalk protocols are supported by every Macintosh.

- AppleTalk for VMS is available for VAX integration.

Disadvantages

- It is not implemented on many large systems.

- AppleTalk is not as suitable for very large networks as TCP/IP.

\section{Recommended Usage}

AppleTalk is a mature technology standard for which support is limited to linkage of Macintosh computers to file and print services. Support for AppleTalk on the site Ethernet LAN is limited to AppleTalk Version 2. It is likely that this protocol will be transitioned to TCP/IP in the future and replaced by OSI in the more distant future. 
Computing Standards and Guldellnes Reference

Document:

Section:

Page:

Issue Date:

Technology Standards

Revision:

WSRC-IM-92.23

$\mathrm{T} 7.9$

2 of 2

$4 / 1 / 92$

Related Standards

TCP/IP

OSI

Support Contact

IRM, Computer and Telecommunications Management Section

References

Inside AppleTalk, 2nd Edition, Apple Computer, Inc. 


\section{SNMP}

\section{Associated Technology Group}

Network Services

Communications Protocols

\section{Description}

Simple Network Management Protocol (SNMP) defines a structure of data values associated with network objects (equipment on a network) called a Management Information Base (MIB) and a communications protocol that allows a management station to query information about the state of a network device and to change the operating characteristics of the device by storing a value in the MIB. SNMP also supports the concept of a "trap" whereby certain operating conditions trigger the transmission of a message from the device to the management station.

SNMP allows a network manager to manage (that is, monitor and configure) a variety of network equipment from a single workstation. SNMP is well supported by network equipment vendors, tut implementations are currently limited to TCP/IP communications protocols.

\section{Advantages}

- $\quad$ SNMP is the de facto industry standard for management of a wide variety of network devices.

Disadvantages

- Implementations of SNMP are largely limited to TCP/IP communications products.

\section{Recommended Usage}

SNMP is a strategic and mature technology standard and is recommended for management of TCP/IP-based communications products. It is expected that OSI management protocols, as yet still evolving, will replace SNMP in the future.

\section{Related Standards}


Support Contact

IRM, Computer and Telecommunications Management Section

References

RFC1157, Simple Network Management Protocol

RFC1156, Management Information Base

RFC 1158, Management Information Base II 


\title{
Kerberos
}

\section{Associated Technology Group}

\author{
Network Services \\ Network Security Services
}

\section{Description}

The Kerberos security service provides facilities for supporting confidentiality in remote procedure calls, a means for authenticating users and services, management of access permissions, and a registry for user account information. This technology originally came out of MIT's Project Athena.

Under Kerberos, a trusted "authentication server" is used to verify users so that network servers are assured of the correct identitics of clients requesting service. Thus, only a single authentication database (which may be replicated for reliability) is required for a network, rather than requiring each server to authenticate all users independently. Authentication procedures use DES encryption of passwords and permissions to provide additional security in a LAN environment.

Kerberos has been adopted by the Open Systems Foundation (OSF) as the Authentication Service provided by the OSF Distributed Computing Environment (DCE). This Authentication Service will be required by the other components of DCE, namely file services and remote procedure calls.

\section{Advantages}

- Kerberos is integrated with a wide collection of services for a distributed

computing environment.

- Major computer vendors (including IBM and DEC) have announced products or

statements of future support for Kerberos.

- Kerberos is part of the OSF DCE standard for network computing.

\section{Disadvantages}

- Kerberos is not widely implemented as yet.

\section{Recommended Usage}

Kerberos is a strategic and mature technology standard and should be used as a technical specification for operating system and network application procurements.

\section{Related Technology Standards}

OSF DCE

DES 
Computing Standards and Guldelines Reference

Technology Standards
Document:

Section:

Page:

Issue Date:

Revision:
WSRC-IM-92.23

T7.11

2 of 2

$4 / 1 / 92$

Support Contact

IRM, Advanced Technology and Architecture Section

References

Kerberos Authentication and Authorization System, M.I.T., Project Athena 


\section{Hardware Interfaces Technology Group}

Description

Hardware interface standards define industry standard (de facto or otherwise) interfaces that are used to join computer system components together. These standards are necessary for vendor independence in selecting components to put together complete computer systems and to join these systems to communications networks. These types of standards are not unlike standards found in the home electronics arena, (e.g., standard component interfaces allow plugging stereo receivers to "foreign" $\mathrm{CD}$ players) or even in plumbing connectors, and they serve the same purpose.

Technology Standards

T8.1 CD-ROM Disk Format (ISO 9660-1988)

T8.2 RS-232

T8.3 RS-449/RS-422/RS-423

T8.4 V.35

T8.5 SCSI

T8.6 Centronics Parallel Printer Interface

\section{Related Technology Standards}

T7.1 Ethernet

T7.2 Token Ring

T7.3 FDDI 


\section{CD.ROM Disk Format (ISO 9660-1988)}

\section{Associated Technology Group}

Hardware interfaces

\section{Description}

ISO 9660 defines the physical attributes, disk format, and directory structure for $C D$ ROM disks used for data or applications storage (not music). While there is not a related FIPS, work is underway to identify the deficiencies and create a FIPS based on this standard.

\section{Advantages}

- ISO 9660 is widely used in the PC (DOS) industry.

- The standard is stable and simple enough that applications that state adherence usually are compatible.

\section{Disadvantages}

- It is primarily oriented toward DOS applications, and is not currently included in a FTPS.

- The disks do not behave as native disks to most computers; that is, they require interface software to appears as "mounted" disks.

\section{Recommended Usage}

This is a mature technology standard and should te used in specifying CD-ROM readers for use with DOS applications, and is a desirable feature for CD-ROM readers for other platforms $2 s$ well. It is not the primary standard for non-DOS CD-ROM readers. While the iSO 9660 standard grew out of the High Sierra format, a High Sierra Croup (HSG) irive will probably not read an ISO 9660) disk, and vice-versa. HSG drives and disks should be avoided.

\section{Related Technology Standards}

None

Support Contact

IRM, Advanced, Technology and Architecture Section

References

Volurne and File Structure of CD-ROM for Information Interchange, Ref. No. ISO 9660:1988 
RS.232

Associated Technology Group

Hardware Interfaces

Description

The Electronic Industries Association (EIA) RS-232 standard defines the industry standard interface for low speed serial data communications. The CCITT V.24 standard closely follows RS-232. Specifically, RS-232 defines the standard between Data Termination Equipment (i.e., a computer or terminal) and Data Communications Equipment (typically a modem). RS-232 C (Version C of the standard) is the rnost common implementation.

The standard provides either asynchronous or synchronous serial communications at data rates up to 20,000 bits per second. The standard defines the number and type of conductors in a multi-wire cable, the shape of the cable connectors, and the signalling conditions. RS.232 is well supported by computer equipinent marufacturers.

\section{Advantages}

- RS-232 has wide industry suppor.

- The standard is stable and often provides a lowest common denominator for connecting dissimilar equipment.

\section{Disadvantages}

- RS-232 supports slow speed applications only.

- Equipment vendors feel free to redefine the configuration of RS-232 connectors, requiring special interface cables to connect equipment.

\section{Recommended Usage}

RS-232 (Level C or D) should be required for asynchronous terminals, serial printers, and slow speed modems.

\section{Related Technology Standards}

RS -4.49

Support Contact

DC\&S

References

ElA Standard RS-232, Interface Between Data Terminal Equipment and Data

Communications Equipment Employing Serial Binary Interchange 


\section{RS. 449 , RS-442, RS.423}

\section{Associated Technology Group}

Hardware Interfaces

Description

The Electronic Industries Association (EIA) RS-449/422/423 standards defines an industry standard interface for moderate speed serial data communications. The CCITT V. 24 standard closely follows these standards. Specifically, RS-449 defines the mechanical, functional, and procedural interface specifications. RS $\mathbf{4 2 2}$ and RS -423 define optional electrical characteristics; RS 422 defines balanced signals and R.S -423 unbalanced signals over the interface. These standards provide great improvements over RS-232 in data communications speed and distances. RS -422 signalling is used in faster data rate applications, supporting rates up to 10 million bits per second.

\section{Advantages}

- These standards have wide industry support.

- They support low, moderate, and high data transfer speeds.

- $\quad$ RS-423 can interoperate with RS-232.

\section{Disadvantages}

- Many vendors provide V.35 interfaces instead of RS-422 for moderate specd applications.

\section{Recommended Usage}

This is a mature technology standard. Specify as an alternative to V.35 for serial communications applications for data rate between 20,000 bits per second and 10 million bits per second. Use RS-232 for lower speed applications.

\section{Related Technology Standards}

ELA RS-232

CCITT V.35

Support Contact 
References

ELA Standard RS-422, Electrical Characteristics of Balanced V'oltage Digital Interface Circuits

EIA Standard RS-423, Electrical Characteristics of Unbalanced Voltage Digital Interface Circuits

EIA Standard RS-449, General Purpose 37-Position and 9-Position Interface Between Data Terminal Equipment and Data Circuit-Terminating Equipment

FIPS Pub 138, Electrical Characteristics of Balanced Voltage Digital Interface Circuits

FIPS Pub 142, Electrical Characieristics of Unbalanced Voltage Digital Interface Circuits 
V. 35

Assuciated Technology Group

Hardware Interfaces

Description

CCITT standard V.35 defines a moderate speed serial interface for linking data communications equipment to data terminal equipment. It provides a higher speed alternative for RS-232 in synchronous serial data communications. V. 35 provides similar capabilities to RS -422 , but is more commonly used than RS-422 for linking high speed communications devices to communications circuits. For example, digital telephone circuits (typically $56 \mathrm{kbps}$ to $1.544 \mathrm{mbps}$ ) are supported by devices called CSU/DSUs. These devices connect to data communications equipment with V.35 interfaces.

Advantages

- V.35 is widely supported in the computer communications industry.

- It provides moderate data transfer speeds (at least $1.5 \mathrm{mbps}$ ).

Disadvantages

- Bulky cable and 34 pin connectors are not compatible with RS-232.

- V.35 is not suitable for very high speed interfaces (T3).

\section{Recommended Usage}

V.35 is a mature technology standard. Specify for serial communications applications for data rates between 20,000 and 2 million bits per second. Use RS-232 for lower speed applications.

\section{Related Technology Standards}

EIA RS-232

RS 449

Support Contact

DC\&S

Reterences

CCITT Recomrnendation V.35, Data Transmission at 48 Kilobits/second Using 60)-108 khz Group Band Circuits 


\section{SCSI}

\section{Associated Technology Group}

Hardw'are Interfaces

Description

Small Computer Systems Interface (SCSI) is an 8-bit bus interface for up to seven cornputer peripherals (disk, tape, CD-ROM, etc.) which allows any two devices to communicate at one time (host to peripheral, peripheral to peripheral). It is commonly used to connect peripherals to microcomputers and workstations.

SCSI (SCSI-1) provides up to 5 million bytes per second data transfer and can connect multiple peripherals while taking only one expansion slot in the computer. SCSI-2 provides command queuing and a "Fast SCSI" synchronous option that provides $10 \mathrm{MB}$ data transfer (8-bit). With a secondary "B" cable for 16- and 32-bit data, "Wide SCSI" provides up to $40 \mathrm{MB}$ transfer (proposed 68-conductor " $\mathrm{P}$ " cable is a single cable solution for 16 bits).

\section{Advantages}

- $\quad$ SCSI is widely used in the PC, Macintosh, and workstation markets.

- The standard is stable and simple enough that applications that state adherence usually are compatible.

- Connection of SCSI devices is simple due to standardization in cabling and minimal allowable configuration parameters.

\section{Disadvantages}

- There is some confusion of SCSI addressing that can cause address conflicts when multiple devices are on the bus.

- The number of devices is limited to seven.

- Interruption of the bus during operations can cause loss of communications to all devices.

\section{Recommended Usage}

This is a mature technology standard. SCSI is a convenient interface for connection of disk drives, scanners, and other peripherals to small computers or workstations. The SCSI interface should be used in an environment of "portable" peripheral connectivity.

\section{Related Technology Standards}

None 
Computing Standards and Guldellnes Reference

Technology Standards
Document:

Section:

Page:

Issue Date:

Revision:
WSRC-IM-92.23

T8.5

2 of 2

$4 / 1 / 92$

Support Contact

DC\&S

References

ANSI X3.131-1986, Small Computers Systems Interface

FIPS Pub 131, Small Computers Systems Interface (SCSI) 


\title{
Centronics Parallel Printer Interface
}

\section{Associated Technology Group}

\author{
Hardware Interfaces
}

Description

The Centronics standard was developed by the Centronics company, which makes computer printers. The Centronics standard is a 36-pin single plug/connector with eight of the 36-pins carrying their respective bits in parallel (eight bits to one character), providing a faster transfer rate than serial transmission, which sends only one bit a time. There are several types of Centronics male and female plugs and receptacles. The pinning (the location of and function of each of the 36-individual wires) is standard from one Centronics cable to another.

\section{Advantages}

- This standard has wide industry support.

\section{Disadvantages}

- Only limited distance are permitted between printer and computer.

- Connector sizes and shapes may vary.

\section{Recommended Usage}

This is a mature technology standard. Specify for printers and for personal computers for attaching printers to personal computers.

\section{Related Technology Standards}

None

Support Contact

DC\&S

References

Centronics Parallel Printer Interface Standard 


\section{Standard Product Groups}

CAST has defined the following Product Groups:

$P 1 \quad$ Desktop Office

P2 High Performance Workstations

P3 Minicompuser Hardware

P4 Data Communications

P5 Relational Database Management Systems

P6 Intrasite Office

P7 Computer Aided Design/Computer Aided Engineering

Note: CAST work to establish site standard products has not been completed. Each time standards for a product group are completed, this document will be updated. 
Document: Sectlon:

Page:

Issue Date:

Computing Acronyms and Torms
WSRC-IM-92.23

Attachment A

1 of 3

$4 / 1 / 92$

10BaseT
ADP
ADSP
AFP
AFS
ANSI
API
AppleTalk
ASC
ASCII
BSRI
C2
CAD
CALS
CASE
CAST
CCF
CCITT
CGM
CSMA-CD
CSU
CTM
DAL
DBMS
DC\&S
DCE
DDP
DEC
DECdns
DECdts
DECnet
DES
DFS
DNA
DTD
DoD
DOE
DOS
DSA
DSU
DUA
EBCDIC
ECMA
EDI
EDIFACT
EIA
ESCC
Ethernet

\author{
Ethernet over Unshielded Twisted Pair Wiring \\ Automated Data Processing \\ AppleTalk Data Stream Protocol \\ AppleTalk Filing Protocol \\ Andrew File System (DCE) \\ American National Standards Institute \\ Applications Program Interface \\ Apple Computer's Communication Protocols \\ Accredited Standards Committee (ANSI) \\ American Standard Code for Information Intercharige \\ Bechtel Savannah River Incorporated \\ Computer Operating System Security Standard \\ Computer Aided Design \\ Computer Aided Logistical Support (DoD standard) \\ Computer Aided Software Engineering \\ Computing Architecture and Standards Team, WSRC \\ Central Computer Facility \\ Consultive Committee for International Telephone and Telegraph \\ Computer Graphics Metafile \\ Carrier Sense, Multiple Access with Collision Detection (Ethernet access) \\ Channel Service Unit \\ Computer and Telecommunications Management Section, IRM \\ Data Access Language (Apple Computer) \\ Database Management System \\ Digital Control and Systems Department, WSRC \\ Distributed Computing Environment (OSF) \\ Datagram Delivery Protocol (AppleTalk) \\ Digital Equipment Corporation \\ DEC distributed name service (DCE) \\ DEC distributed time service (DCE) \\ DEC's Communication Protocols \\ Data Encryption Standard \\ Distributed Filing System (DCE) \\ Digital Network Architecture (basis for DECnet) \\ Document Type Definition (SGML) \\ U. S. Department of Defense \\ U. S. Department of Energy \\ Disk Operating System (as in PC DOS) \\ Directory System Agents (X.500) \\ Data Service Unit \\ Directory User Agent (X.500) \\ Extended Binary Coded Decimal Interchange Code \\ European Computer Manufacturers Association \\ Electronic Document Interchange \\ EDI Protocol \\ Electronic Industries Association \\ Engineering and Scientific Computing Committee \\ Local area network technology (DEC/Xerox/Intel)
}




\begin{tabular}{|c|c|}
\hline FDDI & Fiber Distributed Data Interface \\
\hline FIPS & Federal Information Processing Standard \\
\hline FIPS Pub & Federal Information Processing Standard Publication \\
\hline FTAM & File Transfer, Access, and Mariagement Protocol (OSI) \\
\hline FTP & File Transfer Protocol (TCP/IP) \\
\hline GKS & Graphical Kernel System \\
\hline GOSIP & Government Open Systems Interconnection Profile \\
\hline GUI & Graphical User Interface (winllow-style interface to computer) \\
\hline $\mathrm{IAB}$ & Internet Activities Board \\
\hline EEC & International Electrotechnical Committee \\
\hline IBM & International Business Machines Corporation \\
\hline IEEE & Institute of Electrical and Electronics Engineers \\
\hline IEEE 802.3 & LAN standard for Ethernet \\
\hline IEEE 802.5 & LAN standard for Token Ring \\
\hline IGES & Initial Graphics Exchange Standard \\
\hline IPX & Intemet Packet Exchange (Novell Communications Protocol) \\
\hline IRM & Information Resource Management Department, WSRC \\
\hline ISA & Instrumentation Society of America \\
\hline ISO & International Standards Organization \\
\hline kbps & Kilobit per Second (Thousand bits per second) \\
\hline LAN & Loca! Area Network \\
\hline LAT & Local Area Transport (DEC Communications Protocol) \\
\hline ma & milliamp (analog signal) \\
\hline MAC & Medium Access Control (FDDI) \\
\hline Mac & Macintosh personal computer (Apple Computer) \\
\hline mbps & Megabits per second (one million bits per second transmission rate) \\
\hline MHS & Message Handling System (X.400) \\
\hline MIB & Management Information Base (Network Management Database) \\
\hline MOTIF & Graphical User Interface defined by OSF for X-windows \\
\hline MTA & Message Transfer Agent $(X .400)$ \\
\hline MS-DOS & Microsoft Disk Operating System \\
\hline NCS & Network Computing System (precursor to DCE by Hewlett-Packard) \\
\hline NCSC & National Computer Security Center \\
\hline NIST & National Institute of Standards and Technology \\
\hline Netware & Novell Inc. LAN Operating System \\
\hline NFS & Network Filing System (Sun Computer) \\
\hline ODA & Office Document Architecture \\
\hline ODIF & Office Document Interchange Format \\
\hline ONC & Open Network Computing (UNIX International) \\
\hline OOPS & Object Oriented Programming System \\
\hline $\mathrm{OS} / 2$ & Operating System / 2 (IBM) \\
\hline OSI & Open Systems Interconnection (International Standards Organization) \\
\hline OSF & Open Systems Foundation \\
\hline OS'TI & Office of Scientific and Technical Information (DOE) \\
\hline
\end{tabular}


Document: Section:
WSRC.IM-92-23

Attachment A
Printer Access Protocol (AppleTalk)

Personal Computer (e.g., Macintosh, IBM PS/2)

Process Digital Equipment Committee, WSRC

PHIGS Extensions for $\mathrm{X}$

Programmer's Hierarchical Interactive Graphics System

Physical Protocol (FDDI)

Physical Medium Dependent Protocol (FDDI)

IBM Personal Systems $/ 2$ personal computer

Portable Operating System Interface (IEEE)

Remote Data Access

Relational DataBase Management System

Request For Comment (TCP/IP standards from Internet Activities Board)

Request For Quotation

Request For Technology

Remote Procedure Call

Recommended Standard (EIA)

Rivest, Shamir, Adleman encryption algorithm

Rich Text Format

Systems Applications Architecture (IBM)

Small Computer Systems interface

Standard Generalized Markup Language

Station Management Protocol (FDDI)

Systems Network Architecture (IBM Communications Protocols)

Simple Network Management Protocol

Structured Query Language

Savannah River Site

Standard for The Exchange of Product model data

Transmission Control Protocol / Internet Protocol

Terminal Communications Protocol (TCP/IP)

Tagged Image File Formai

User Agent (X.400)

Unclassified Controlled Nuclear Information

Portable operating system (trademark of AT\&T)

Unshie'ded Twisted Pairs

Primary DEC computer family

Virtual Memory System (VAX operating system)

Virtual Terminal Protocol

$A D E C$ character-based terminal

EDI Protocol

Electronic Messaging Protocol (OSI)

Directory Services Protocol (OSI)

Westinghouse Savannah River Company

Consortium promoting interoperability of UNIX systems

Xerox Network Systems (LAN protocol)

$X / O p e n$ Portability Guide Version 3

Standard for device-independent text and image network terminals 


\begin{tabular}{|c|c|c|c|c|}
\hline Computing & Standards and Guldelines & - Reference & $\begin{array}{l}\text { Dociument: } \\
\text { Soction: } \\
\text { Page: } \\
\text { lgsue Date: } \\
\text { Revislon: }\end{array}$ & $\begin{array}{r}\text { WSAC.IM-92.23 } \\
\text { Attachment B } \\
1 \text { of } 2 \\
4 / 1 / 92\end{array}$ \\
\hline
\end{tabular}

The following organizations produce documents that describe texhology standards guidelined in this document. The following tist provides an ordering address and phone number for contucting each organization. The Technical Library in SRTC (773-A) can provide assistance in obtaining copies of standards documents.
ANSI, Amerlcan Natlonal Standards Institutio
Approved Starudards:
Draft Standards:
ANSI siales riepartmert
$11 \mathrm{~W} 43 . \mathrm{st}$
New York, NY 100336
Phone: $(212) 642-49100$
Global Engineering
1990 M St. NW, Suite 400
Washington, DC 20036
Phone: (800) $854-7179$

\section{CCITT, International Telegraph and Telephone Consultive Cominitteo}

National Techuicul Infomation Service

5285 Port Royal Raad

Springfield. VA 22161

Phone: $(703,487+4600$

\section{DOD, U.S. Depariment of Defense: DOD-STDS, MIL-STDS, MIL-SPECS}

Defense Technical Information Center (DTTC)

ATTN: FDRA

Cumeron Station

Alexandria, VA 22304-\$145

Phone: (703) 274.7633

\section{EIA, Electronic Industrles Association}

Electronic Industries Assoriation

1722 Eyc Street, NW. Suite 300

Washington, D.C. 20006

Phone: $(202) 45 \%-4900$

IEEE, Instltute of Electrical and Electronlcs Engineers, Inc.

IEEE Standards Office

H45 Hoes Lane

Piscalaway, NJ 0885

Phone: (9018) 562.3800

\section{ISA, Instrument Society of Americe.}

Instrument Sosiety of Annerica

67 Alexander Drive. P. O. BO. $1227 \%$

Reserarch Trias.gle Park, NC 27709

Phone: $(919,549.8411$ 
NIC, Internet Network Information Center: RFCs

SRI International, Inc.

Network Infonnation Center

333 Ravenswond Ave.

Menlo Park, CA 94025

Phone: (800) 235.3155

\section{ISO, International Standards Organization}

ANSI Sales Deparument

11 IN $42 \mathrm{St}$

New York, NY 10036

Phone: (212) 642.4900

\section{NCSC, National Computer Security Center}

National Computer Security Center

9800 Savage Raad

Fort Meade, MD 20755-6000

Phone: (301) 859.4452

\section{NIST, National Institute for Standards and Technology}

U.S. Department of Commerce

National Institute for Standards and Technology

Admin Bldg A4l

Gaithersburg, MD 20899

Phone: (301) 975-2000

\section{NTIS, National Technical Information Service: FIPS Pubs}

U. S. Department of Commerce

National Technical Information Service

Springfield. VA 22161

Phone: (703) 487.4650

Open Software Foundation, Inc.

Open Software Foundation, Inc.

11 Cambridge Cus

Cambridge, MA 02142

Phone: (617) 6.21-8700

\section{X/Open Company, Lid}

X/Open Company, Lid

1750 Montgomery Street

San Franc:sco, CA 94111

Phone: (415) 323.7992 


\section{BUANR PAGE}




\section{Purpose}

It is WSRC policy that site computing activities be based on standards (Reference 1). The primary reasons for defining the site's computing standards and guidelines are to promote interoperability of site computing systems and to facilitate the portability of programs, applications, and data between computer systems. This policy is necessary to obtain increased flexibility and cost effectiveness in carrying out the site mission.

The SRS computing standards will depend heavily on national and international standards, although standardization on dominant proprietary standards and on specific products will be required to reduce the total number of computer products supported at the site to a more manageable set. In other words, the emphasis on standards will be two-fold: standardization on the technologies required for information and process control systerns integration, and standardization on specific products in order to koep the number of specific computer products that must be supported on the site to a manageable and economical set. Ideally, standard produxts will conform to the technology standards. However, there will be cases where existing standard products do not conform totally to the tochnology standards yet remain supported for reasons of continuity and economics.

A site-wide Computing Council has been formed (Reference 2) 10 coordinate and integrate computing activities at SRS. This organization consists of senior management representing exch site division. It oversees the development and implementation of the site strategic computing vision in support of the site mission. The working arm of the Computing Council is the Computing Architecture and Standards Team (CAST). CAST is made up of representatives from all site divisions as well as other organizations that represent communities interested in computing, such as the Process Digital Equipment Committe (PDEC), the Engineering/Sciensific Computer Committee (ESCC), and the Management Informations Systems Committee. CAST membership is knowledgeable in computing tochnologies and the use of computing to help perform the site's mission. This body is instrumental in setting standards for site computing and creating the site's computing architecture, as well as recommending computing policies to the Computing Council for consideration.

\section{Technology Standards}

A computing technology standard is defined by some international, nationas, industry consortium, or individual corporation as a standard way of accomplishing specific computing tasks or functions. These standards are "open" in the serse that the governing bodies publish the specifications in complete detail so that vendors may develop products that conform to the standards. In many cases the governing body for a standard will test and certify those vendor products that conform to the technology standard. 

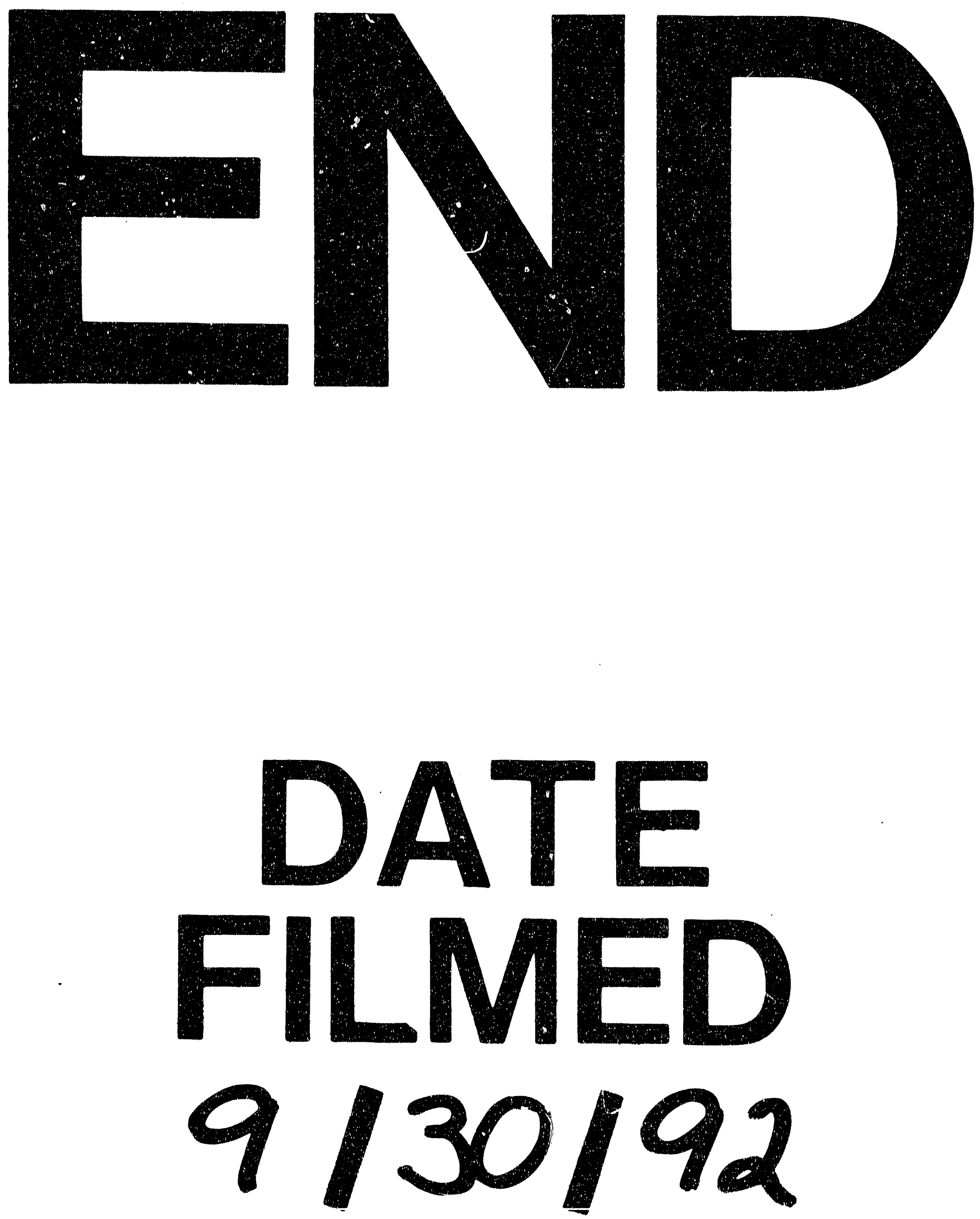

事 
$\bar{\equiv}$ 